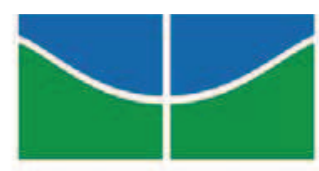

Universidade de Brasília

Faculdade de Economia, Administração, Contabilidade e Ciência da Informação e Documentação (FACE)

DENISE DE SOUSA VIEIRA

MARIA LÚCIA SOARES NEVES

MAPEAMENTO DAS COMPETÊNCIAS ORGANIZACIONAIS DE UM HOSPITAL UNIVERSITÁRIO E DE SUAS PRINCIPAIS UNIDADES 
DENISE DE SOUSA VIEIRA

MARIA LÚCIA SOARES NEVES

\section{MAPEAMENTO DAS COMPETÊNCIAS ORGANIZACIONAIS DE UM HOSPITAL UNIVERSITÁRIO E DE SUAS PRINCIPAIS UNIDADES}

Monografia apresentada à Faculdade de Economia, Administração, Contabilidade e Ciência da Informação e Documentação (FACE), da Universidade de Brasília, como requisito parcial à obtenção do grau de Especialista em Gestão Universitária.

Orientadora: Prof ${ }^{a}$ Dra. Maria de Fátima Bruno de Faria

$$
\text { Brasília - DF }
$$


DENISE DE SOUSA VIEIRA

MARIA LÚCIA SOARES NEVES

\section{MAPEAMENTO DAS COMPETÊNCIAS ORGANIZACIONAIS DE UM HOSPITAL UNIVERSITÁRIO E DE SUAS PRINCIPAIS UNIDADES}

Monografia apresentada à Faculdade de Economia, Administração, Contabilidade e Ciência da Informação e Documentação (FACE), da Universidade de Brasília, como requisito parcial à obtenção do grau de Especialista em Gestão Universitária. Data de aprovação

Prof $^{\mathrm{a}}$ Dra. Maria de Fátima Bruno de Faria Orientadora

Profa Dra. Catarina Cecília Odelius Membro da Banca Examinadora 
A todas as pessoas que desejam o nosso sucesso, em especial às nossas famílias. 


\section{AGRADECIMENTOS}

Agradecemos a Deus, que guia os nossos passos e é a nossa fonte de inspiração, nosso abrigo nos instantes de dor e aflição, nossa morada nos momentos de paz e alegria.

À orientação cuidadosa e a atenção da Professora Fátima Bruno.

A todos os funcionários e em especial aos Diretores Adjuntos e Chefes de divisões do Hospital Universitário de Brasília, que nos permitiu realizar este trabalho.

A todos os funcionários do PPGA e da FACE em especial a Vera Lúcia Cavalcante Correa de Oliveira pela atenção dispensada.

A todos os professores do Curso de Especialização especialmente o professor César Augusto Tibúrcio Silva pelo empenho na realização do curso e pela dedicação dispensada a todos os alunos.

E, finalmente, agradecemos a todos os colegas e amigos do Curso de Especialização que de alguma forma contribuíram para o sucesso desta conquista. 


\section{RESUMO}

O objetivo desta pesquisa foi identificar as competências organizacionais de um hospital universitário e de suas principais unidades. Por meio de uma revisão bibliográfica, buscou-se revisar conceitos e pesquisas referentes à competência, especialmente, tratar das principais definições sobre competências organizacionais e estudos relacionados ao processo de mapeamento de tais competências. A coleta de dados foi realizada por meio de pesquisa documental, entrevista semi-estruturada e questionário. O trabalho foi dividido em duas etapas. Na primeira etapa foram realizadas entrevistas individuais com quatro diretores do hospital, objetivando identificar as competências organizacionais do hospital e de suas principais unidades. Os dados qualitativos foram analisados utilizando a técnica de análise de conteúdo. Como resultado, 13 competências foram identificadas. Na segunda etapa, foi aplicado um questionário para os chefes das 18 principais unidades ligadas às diretorias com o objetivo de identificar o grau de importância e o grau de domínio das competências organizacionais, de acordo com a percepção de cada respondente. A partir da avaliação do grau de importância e do grau de domínio, foram calculados índices de prioridade e de desenvolvimento das referidas competências organizacionais. Os dados evidenciam que essas competências possuem graus que variam entre muita e extrema importância, mas sugerem, também, que para algumas competências o grau de domínio varia entre pouco e médio, necessitando de ações da organização no sentido do seu desenvolvimento. As competências identificadas como prioritárias foram: Difundir nova cultura de humanização; Propiciar a infra-estrutura essencial ao funcionamento do Hospital; Oferecer as condições para a prestação de atendimento aos pacientes e Incentivar e promover o desenvolvimento das atividades de pesquisa e extensão no Hospital Universitário de Brasília (HUB). Conclui-se que o mapeamento das competências da Instituição pesquisada é de extrema importância, pois poderão servir como elemento que ajudará a traçar políticas e ações futuras, fortalecendo assim, o processo de apoio para a tomada de decisão objetivando a excelência dos serviços prestados pela Organização.

Palavras Chave: Competências Organizacionais, Administração Pública, Hospital Universitário, Mapeamento de Competências. 


\section{LISTA DE FIGURAS}

Figura 1: Competências como fonte e valor para o indivíduo e para a organização ....18

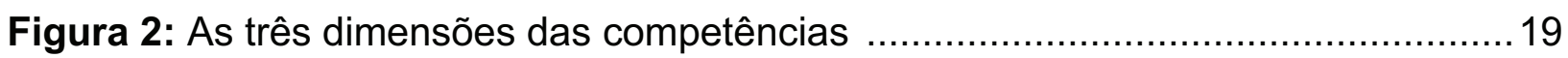

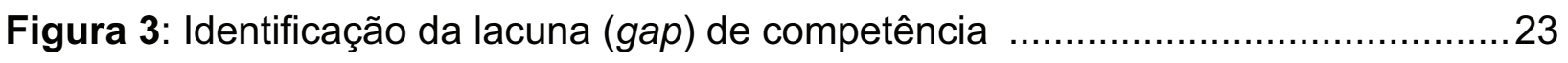

Figura 4: Identificação da lacuna (gap) de competência ...................................24

Figura 5: Modelo de Gestão de Desempenho baseado nas Competências ...............25

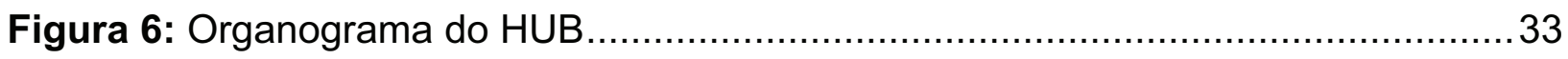




\section{SUMÁRIO}

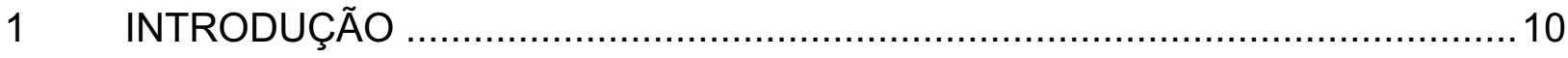

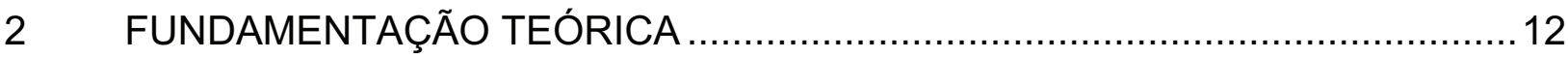

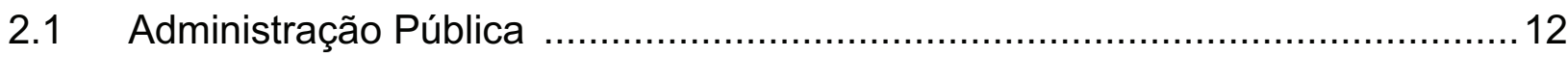

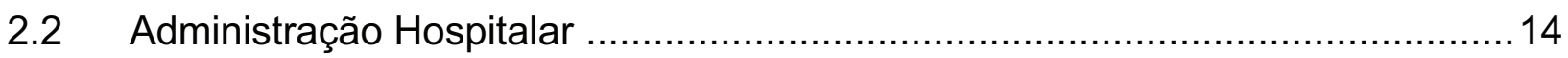

2.3 Noções de Competência ............................................................................ 16

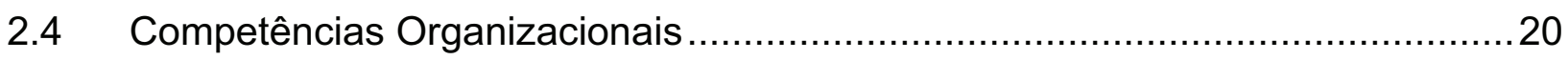

2.5 Processo de Mapeamento de Competências Organizacionais ..........................23

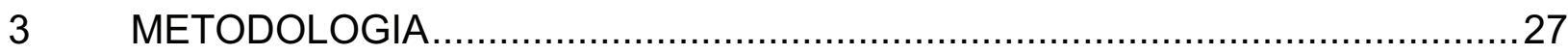

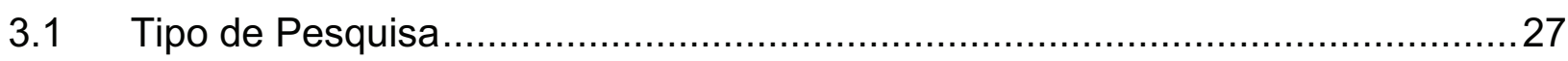

3.2 Amostra de documentos e participantes da pesquisa .....................................28

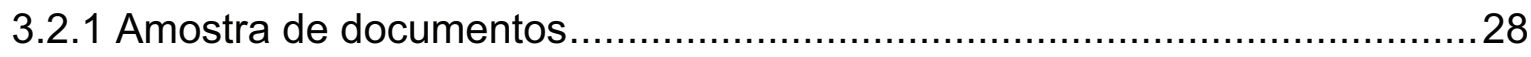

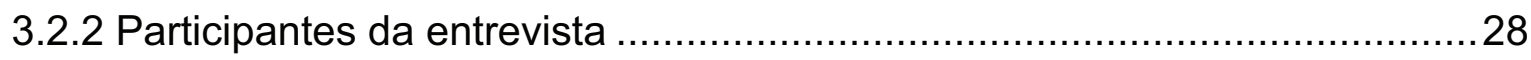

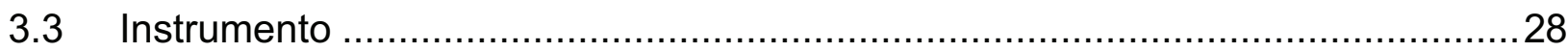

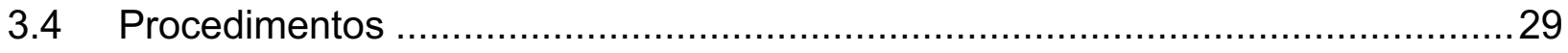

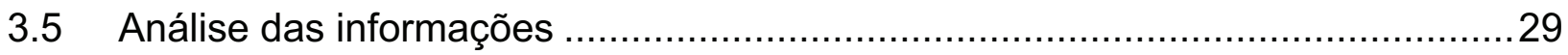

4 RESULTADOS E DISCUSSÃO

4.1 Caracterização da Instituição e dos Participantes da Pesquisa .............................31

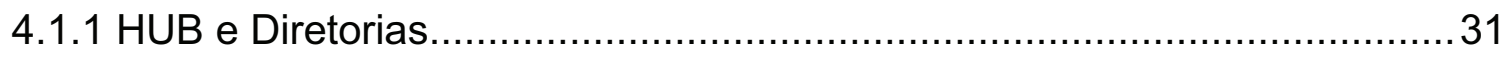

4.1.2 Participantes das Entrevistas ………….............................................. 34

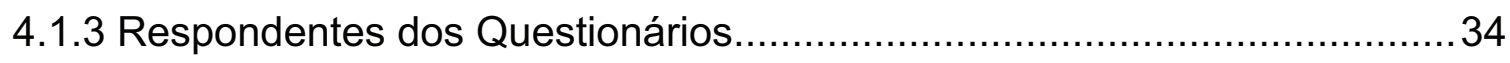

4.2 Definição das Competências Organizacionais do HUB e Diretorias ...................34

4.3 Graus de importância, domínio e prioridade das competências organizacionais

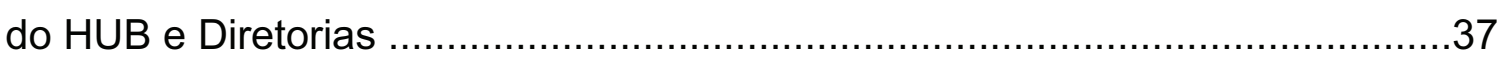

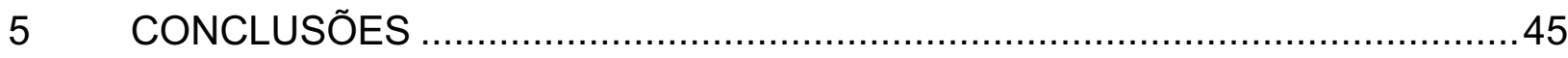


REFERÊNCIAS 


\section{INTRODUÇÃO}

As organizações contemporâneas estão inseridas em um contexto que envolve muita competitividade exigindo desenvolvimento constante e elevada capacidade de adaptação. Assim, é de relevante importância conhecer as competências de uma organização para adequá-la às necessidades do usuário e para que possam ser identificados aspectos que necessitam ser aprimorados, a fim de que a organização apresente desempenho efetivo.

Para se manterem competitivas em um cenário de mudanças rápidas as exigências são muitas, tais como: novas tecnologias, novas formas de pensar a qualidade, construção e alavancagem de novas competências. No caso das organizações públicas, o foco não recai na competitividade, mas na prestação de serviços de qualidade ao cidadão.

Pressionadas por melhorias dos serviços prestados, as organizações buscam modelos de gestão mais eficazes que resultem na melhoria da qualidade dos produtos e dos serviços oferecidos aos cidadãos que estão cada vez mais exigentes e conscientes dos seus direitos.

Segundo Carbone et al. (2006), a gestão por competências é um modelo de gestão que sugere o alinhamento de esforços para que as competências humanas possam gerar e sustentar as competências organizacionais necessárias para que os objetivos estratégicos da organização sejam alcançados. Partindo do contexto, os autores consideram a gestão por competências um modelo gerencial que figura como alternativa aos tradicionalmente utilizados pelas organizações, que se baseia no pressuposto de que a organização deve dominar certas competências, aquelas difíceis de serem imitadas, que dão a ela um desempenho superior às demais.

Borba (1991) considera que as Organizações Hospitalares e Sistemas de Saúde são de grande importância no contexto nacional e internacional e suas ações provocam repercussões nos ambientes econômico, político, social e cultural. Atualmente, a capacidade das Organizações Hospitalares em empregar seus recursos de forma mais eficiente e eficaz, não apenas influencia diretamente seus resultados, como afeta até mesmo sua capacidade de sobrevivência no mercado.

Para adequar-se a essas mudanças, a Administração das Organizações Hospitalares evoluíram da simples integração e funcionamento de seus sub- 
sistemas operacionais para um processo mais complexo de diagnósticos e análises gerenciais, com os seguintes objetivos: adquirir referências que possibilitam pensar e agir estrategicamente frente aos desafios da Gestão de Organizações Hospitalares e Sistemas de Saúde e desenvolver competências técnicas e gerenciais contemporâneas que permitam identificar e apresentar soluções aos problemas fundamentais que afligem a área de saúde.

Ao considerar que mapear as competências de uma organização é de suma importância, pois é uma ferramenta que auxilia de maneira eficiente os processos de gestão e organização, o presente trabalho tem como objetivo identificar as competências organizacionais de um hospital universitário e de suas principais unidades, através de pesquisa a ser realizada junto à direção e suas principais unidades. Essas competências poderão orientar as ações do hospital, no sentido de aprimorar o seu desempenho futuro. 


\section{FUNDAMENTAÇÃO TEÓRICA}

O presente capítulo apresenta os resultados obtidos por meio de pesquisa bibliográfica, onde buscou revisar conceitos e pesquisas referentes a competências, bem como, tratar das principais definições sobre competência organizacional e estudos relacionados ao processo de mapeamento de tais competências, com o objetivo de embasar os conhecimentos necessários para o desenvolvimento da pesquisa.

\subsection{Administração Pública}

A necessidade de administrar surge do confronto entre as variáveis que compõem uma atividade formalmente estruturada, como recursos materiais e humanos, tecnologia, restrições ambientais, entre outros.

Todas as organizações são constituídas de pessoas e de recursos nãohumanos. A vida das pessoas depende das organizações e a organização para continuar depende do trabalho destas pessoas. As pessoas nascem, crescem, aprendem, vivem, trabalham e se divertem, são tratadas e morrem dentro das organizações. As organizações são extremamente heterogêneas e diversificadas (CHIAVENATO, 1993).

Uma instituição de serviço público, na maioria dos seus aspectos, não difere muito de uma empresa, precisa enfrentar desafios semelhantes ou idênticos para tornar o trabalho produtivo. Mas fundamentalmente o seu negócio é diferente de uma empresa. A finalidade, seus valores e objetivos são diferentes. O serviço público não é normalmente administrado visando um desempenho eficaz (MEIRELLES, 2000).

Segundo Meirelles (2000), a Administração Pública apresenta sua estrutura e as atividades relacionadas ao Estado, sobre a qual repousa a concepção moderna de organização e funcionamento dos serviços.

O direito administrativo é responsável pela Administração e imposição de regras jurídicas de organização e funcionamento do complexo estatal, onde as técnicas de administração indicam os instrumentos e a conduta mais adequada ao pleno desempenho das atribuições da Administração. 
Os órgãos, portanto, devem distribuir as funções, fixar as competências e capacitar os agentes para a satisfatória prestação dos serviços públicos ou de interesse coletivo, com o objetivo final e supremo do Estado em todos os setores do Governo e da Administração.

Dentre as organizações de serviços públicos, encontram-se: órgãos da administração direta, órgãos da administração indireta empresas públicas, sociedades de autarquias mistas, fundações e afins. A pluralidade de estruturas, não necessariamente constituído um conjunto ordenado de agentes, tendo como características comuns o fato de terem-se originado de uma mesma fonte, o Estado. (TACHIZAWA; SCAICO, 1997).

A Administração pública realiza sua função utilizando atos administrativos, principalmente, por meio de órgãos do Poder Executivo. No entanto, não há restrições quanto aos Poderes Legislativos e Judiciários em praticarem tal ato. A finalidade do ato Administrativo é aquela que a lei indica explícita ou implicitamente, todavia, não cabe ao administrador escolher outra, ou substituir a indicada.

A Reforma do Estado de 1995 substituiu a Administração Pública Burocrática, a qual exercia práticas clientelistas ou patrimonialistas por uma Administração Pública Gerencial que passou a adotar princípios da "nova gestão pública" (BRESSER- PEREIRA, 1997).

Portanto, pode-se afirmar que a reforma da Administração Pública, em curso no Brasil, representou uma inovação na agenda do governo e trouxe os temas do fortalecimento da capacidade de governo, eficiência e melhoria da qualidade dos serviços públicos prestados aos cidadãos. Para alcançar tais resultados, a reforma propôs uma mudança no quadro constitucional legal, a criação de novos formatos institucionais, ocasionando a mudança da cultura burocrática para a cultura gerencial e novos instrumentos de gestão pública.

Bresser-Pereira (1998) considera a Gestão pela Qualidade Total como principal estratégia de gerenciamento a ser adotada pelo Estado. Esse controle é uma estratégia empresarial adequada ao gerenciamento público por adotar vários critérios de excelência, além da simples taxa de lucros, que não existe no governo. Pode-se descentralizar, controlar por resultados, incentivar a competição administrativa, colocar o foco no cliente, mas a descentralização envolve o controle 
democrático, os resultados desejados devem ser decididos politicamente, o cliente não é apenas cliente, mas um cliente-cidadão revestido de poderes que vão além dos direitos do cliente ou do consumidor.

$\mathrm{Na}$ Administração Pública os servidores pautam suas decisões e ações baseadas nos princípios estabelecidos na Constituição de 1988, Art 37 "A administração pública direta e indireta de qualquer dos Poderes da União, dos Estados, do Distrito Federal e dos Municípios obedecerá aos princípios de legalidade, impessoalidade, moralidade, publicidade e eficiência" (BRASIL, 1988, p.36). Esses são os cinco princípios norteadores da Administração Pública.

\subsection{Administração Hospitalar}

Foucault (1981) afirma que os primeiros hospitais datam do final do século XVIII, período em que a Academia de Ciências da França buscava definir uma padronização para os hospitais existentes, realizando assim viagens de pesquisa, com o intuito de estudar aspectos físicos e funcionais para transformar os depósitos de doentes da época em instituições que buscassem a assistência à saúde, como um local de prática médica.

Nesse período, a formação médica não incluía atividade hospitalar. Após essa fase, houve uma evolução hospitalar focada nos pacientes e realizadas pelos médicos, cujo trabalho era observar o comportamento dos doentes e tentar auxiliar a natureza no processo de cura, que acabou transformando-se em uma atividade rotineira (FOUCAULT, 1981).

O hospital surgiu no Brasil em 1543, quando após o descobrimento, percebeu-se a necessidade de acolher os marujos e forasteiros nessas unidades. Hoje, o hospital é parte integrante de uma organização médica e social que desempenha a função de assistência curativa e preventiva da população (MAUDONNET, 1988).

Maudonnet (1988) afirma que novos hospitais foram sendo construídos e apresentaram uma sucessão de modelos:

a) Tradicional: com característica de obra filantrópica, inspirado na caridade. 
b) Assistencial: sem finalidade lucrativa, dirigido por associações privadas.

c) Público, federal, estadual ou mental: destaca-se pelo desenvolvimento de atividades de atendimento emergencial, laboratorial e para atender os doentes mentais, dentre outras.

d) Privado: com finalidade lucrativa, vendendo os produtos sob fiscalização estatal.

A organização hospitalar é semelhante a uma empresa pelas funções administrativas apresentadas. Nos dias atuais, o hospital apresenta-se como um instrumento de intervenção terapêutica com o objetivo de alcançar a cura de doentes (GURGEL JÚNIOR; VIEIRA, 2002).

Borba (1991) destaca que o administrador hospitalar deve apresentar como requisitos a efetiva e eficiente administração para o processo de desenvolvimento da unidade de saúde. Portanto, necessita de informações e conhecimentos a respeito de suas funções, a fim de oferecer o necessário para garantir o efetivo atendimento aos beneficiários dos serviços de saúde. Cabe ao administrador hospitalar ainda, responder pela qualidade dos serviços e cuidados prestados, formação e composição do corpo clínico, adequada visão da função hospitalar e definição clara da estrutura orgânica. "O administrador eficaz não confunde o verdadeiro problema com os sintomas cujo tratamento resulta apenas num alívio temporário e não remove as causas" (BORBA, 1991, p, 25).

Gurgel Júnior e Vieira (2002) consideram a organização hospitalar como uma das mais complexas, pela nobreza e amplitude da sua missão, além de apresentar equipe multidisciplinar com elevado grau de autonomia, para dar assistência à saúde em caráter preventivo, curativo e realibilitador a pacientes em regime de internação, onde se utiliza, rotineiramente e de forma crescente, tecnologia de ponta. Além de ser um espaço de prática de ensino-aprendizagem e produção científica.

Mintzberg (1995) aponta a administração hospitalar como burocrática do ponto de vista estrutural, onde o setor operacional tem importância e concentra o poder na organização. Gurgel Júnior e Vieira (2002) complementam afirmando que a padronização de habilidades realizadas por órgãos fiscalizadores externos das diversas categorias profissionais confere autonomia e independência à gerência estratégica, pois as habilidades profissionais são definidas fora da organização em 
cursos profissionalizantes, ou seja, o estado da arte é um atributo das próprias corporações que desenvolvem seu trabalho no hospital.

As mudanças ocorridas no Sistema de Administração Pública passam a exigir adoção da Gestão de Pessoas por Competências no sentido de contribuir para o desenvolvimento profissional alinhado às estratégias organizacionais.

Assim sendo, independentemente do modelo hospitalar, ele está inserido em um complexo ambiente, em que exige um funcionamento que atenda aos seus usuários.

\subsection{Noções de competência}

O conceito de competência vem sendo construído ao longo dos últimos anos. Portanto, não é um conceito novo e várias são as interpretações dadas ao termo.

O debate sobre competência iniciou com a publicação, em 1973, de artigo de autoria de McClelland e deu-se em debate entre psicólogos e administradores nos Estados Unidos. Na visão de Mirabile (1997 apud FLEURY; FLEURY, 2001), a competência é uma característica subjacente a uma pessoa que é casualmente relacionada com desempenho superior na realização de uma tarefa ou em uma determinada situação.

Fleury e Fleury (2001) destacam que, nos anos 90, o termo competência era utilizado no vocabulário das organizações produtivas em um momento marcado pelo desenvolvimento das políticas de emprego orientadas pela busca de flexibilidade nas empresas e mudanças na gestão de pessoas. Essa terminologia tem sido reconhecida pelas organizações produtivas, instituições educacionais como substituta da noção de qualificação profissional nos postos de trabalho.

Segundo Fleury e Fleury (2001), somente nos últimos anos o tema competência começou a ser discutido por acadêmicos e empresários, associado a diferentes níveis de compreensão: da pessoa (as competências do indivíduo), das organizações (as core competences) e dos países (sistemas educacionais e formação de competências).

Para Hoffman (1999 apud BORGES-ANDRADE et al., 2006) não existe uma única definição amplamente aceita para o termo competência. Existem os que 
definem competência como desempenho sustentável; há os que se referem ao termo como desempenho observável; há ainda os que se referem a um padrão de qualidade do desempenho de pessoas, e, finalmente, os que usam o conceito de competência para referir-se aos atributos subjacentes de uma pessoa.

A palavra competência é utilizada na linguagem comum das pessoas com significados diversos, tais como: conjunto de conhecimentos ou habilidades, aptidão ou ainda autoridade atribuída a um individuo por seu cargo ou sua função, atribuição (HOUAISS, 2004).

No entanto, nas colocações de Borges-Andrade et al. (2006), os que consideram competências como desempenho observável partem de uma perspectiva behaviorista. O foco, nesse caso, é na tarefa a ser completada. Assim sendo, ele define competência pelas saídas de um sistema de trabalho nem sempre explícitas. O resultado pretendido é o treinamento de pessoas nos aspectos relevantes de um cargo. O desempenho é definido de forma mensurável, de modo a poder ser observado ensinado, aprendido e avaliado.

Outra definição de Borges-Andrade et al. (2006) é a que focaliza padrões de desempenho ou excelência no desempenho. Esta definição orienta o esforço individual para a superação, em busca de maior produtividade ou eficiência. Nesse, o desempenho individual é conectado a objetivos e a estratégia da organização como um todo. Nesse contexto, competência significa que um alto padrão de desempenho é alcançado.

Fleury e Fleury (2001) mencionam que o conceito de competência, para alguns autores, está baseado na tarefa e no conjunto de tarefas referentes a um cargo. Assim, o conceito de competência é visto como um conjunto de conhecimentos, habilidades e atitudes que justificam um alto desempenho, acreditando que os melhores desempenhos estão fundamentados na inteligência e personalidade das pessoas.

O termo competência é ainda relacionado aos atributos subjacentes de uma pessoa ou ao conjunto de conhecimentos, habilidades e atitudes de um indivíduo, que Ihe permitirão produzir um desempenho competente. O foco da definição está nas entradas (inputs) requeridas para que sistema de trabalho possa operar (BORGES-ANDRADE et al., 2006). 
Para Fleury e Fleury (2001) a competência não se limita a um estoque de conhecimentos teóricos e empíricos detido pelo indivíduo, nem se encontra encapsulada na tarefa. A competência do individuo não é um estado, não se reduz a um conhecimento ou know how específico. As competências são sempre contextualizadas. Os conhecimentos e o know how não adquirem status de competência a não ser que sejam comunicados e utilizados.

A competência é definida por Fleury e Fleury (2008, p. 188) como, "um saber agir responsável e reconhecido, que implica mobilizar, integrar, transferir conhecimentos, recursos e habilidades, que agreguem valor econômico à organização e valor social ao individuo", conforme ilustra a Figura 1.

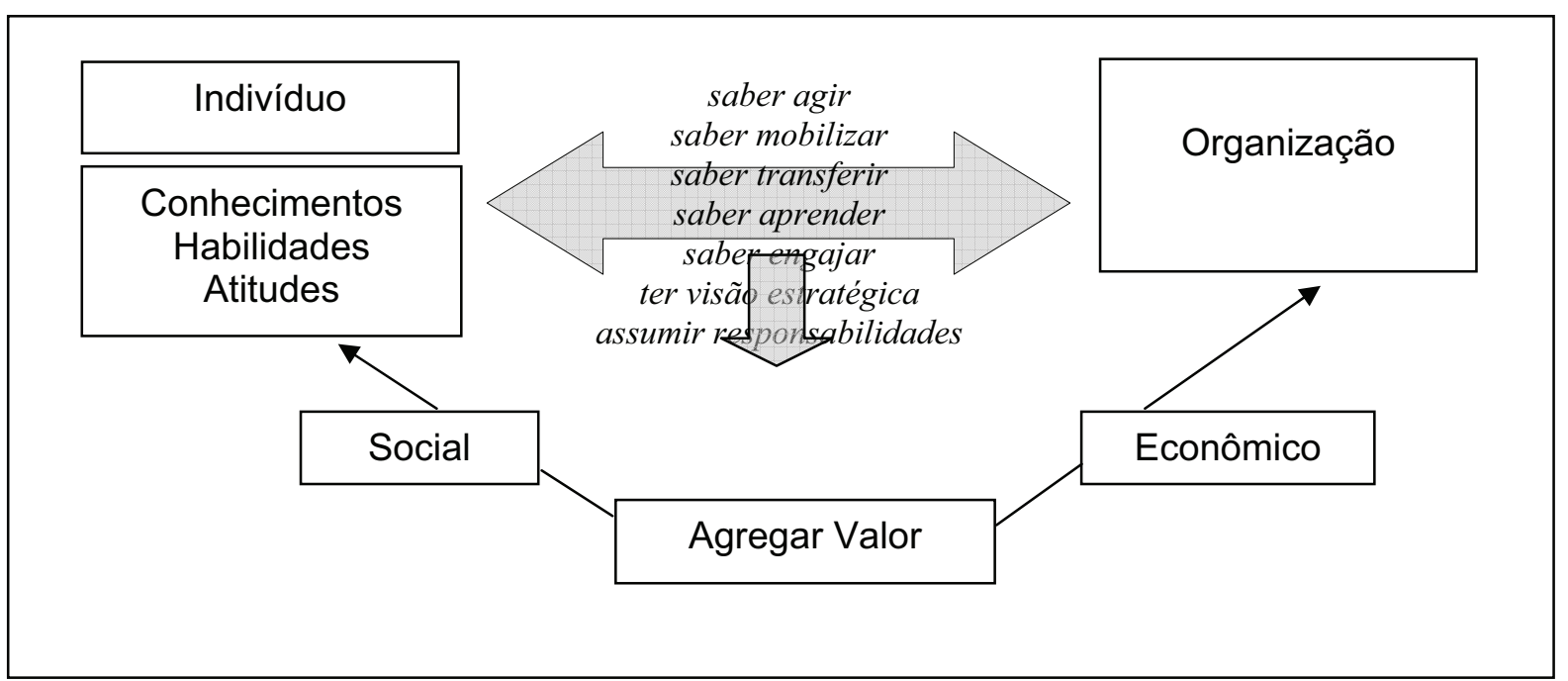

Figura 1: Competências como fonte e valor para o indivíduo e para a organização Fonte: Fleury e Fleury (2001, p. 188)

A noção de competência, segundo Brandão et al. (2007), caracteriza-se como complexa e multifacetada, podendo ser interpretada de diferentes maneiras. Embora esse conceito tenha emergido na área de administração, algumas teorias, pesquisas e proposições de outras áreas de conhecimento, como a Psicologia Social e Organizacional, ajudam a compreender a natureza da competência e de seus componentes.

Durand (2000 apud BRANDÃO; GUIMARÃES, 2001) adotando as idéias do pedagogo suíço Henri Pestalozzi, que idealizou a educação como desenvolvimento natural, espontâneo e harmônico das capacidades humanas que se revelam na tríplice atividade da cabeça, das mãos e do coração, construiu um conceito de 
competência com base em três dimensões: a) conhecimentos, b) habilidades e c) atitudes. A tríade sugerida por Pestalozzi (1974 apud BRANDÃO; GUIMARÃES, 2001), envolve não apenas questões técnicas, mas também a cognição e as atitudes relacionadas ao trabalho, conforme a Figura 2.

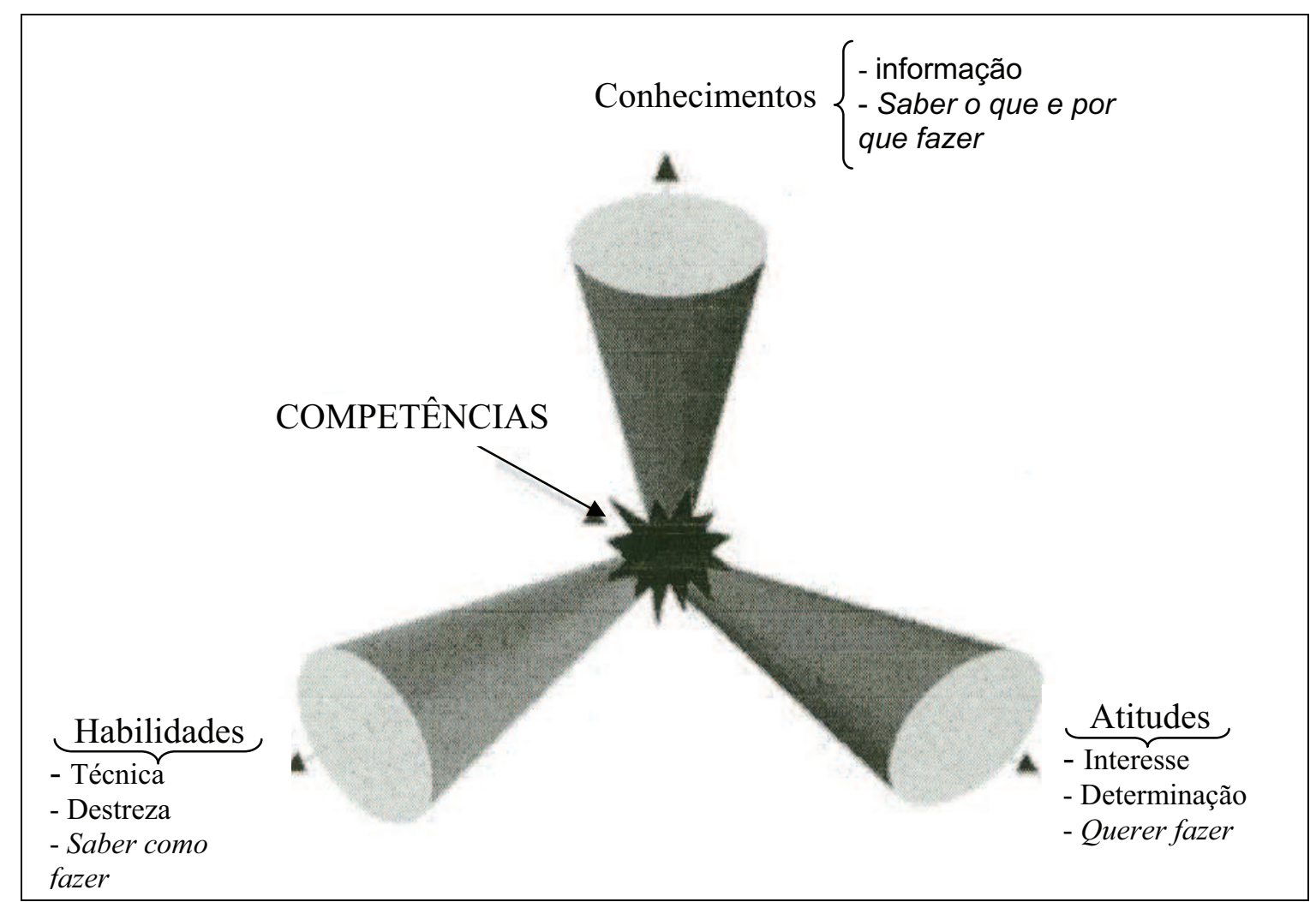

Figura 2: As três dimensões das competências

Fonte: adaptado de Durand (1998 apud BRANDÃO; GUIMARÃES, 2001, p. 10)

As três dimensões que apóiam o conceito de competência são definidas por Durand (1998 apud BRANDÃO; GUIMARÃES, 2001, p. 4) da seguinte maneira:

a) Conhecimento: corresponde a uma série de informações assimiladas e estruturadas pelo individuo, que lhe permite "entender o mundo". Incluí a capacidade de receber informações e integrá-las dentro de um esquema preexistente, o pensamento e a visão estratégica, o saber "o que" e o "por quê";

b) Habilidade: refere-se à capacidade de aplicar a fazer uso produtivo do conhecimento, ou seja, agir de acordo com objetivos ou processos predefinidos, envolvendo técnica e aptidão;

c) Atitude: diz respeito a aspectos afetivos e sociais relacionados ao trabalho. Inclui a identidade do individuo com os valores da organização e, por 
conseqüência, seu comprometimento e motivação para atender aos padrões de comportamento esperados para atingir resultados no trabalho com alto desempenho.

Segundo Brandão e Guimarães (2001), a competência não é um conhecimento exato e sim uma questão humana, ela não pode ser medida pelos sistemas tradicionais de pontuação, e sim por métodos qualitativos de julgamento, que implicam também em aspectos subjetivos. Como a competência pode ser avaliada, então é possível a certificação da competência. A avaliação é a ponte entre a certificação e a competência.

Ainda que até aqui se tenha tratado da competência como atributo associado ao indivíduo é possível relacioná-la, também, a equipes de trabalho e a organizações.

\subsection{Competências organizacionais}

Segundo Mills et al. (2002 apud FLEURY; FLEURY, 2007), a origem do conceito de competência organizacional tem base na abordagem da organização como um portfólio de recursos: físico (infra-estrutura), financeiro, intangível (marca, imagem etc), organizacional (sistemas administrativos, cultura organizacional) e recursos humanos, de modo que:

Um recurso é algo que a organização possui ou tem acesso, mesmo que esse acesso seja temporário... uma competência é uma habilidade para fazer alguma coisa... uma competência é construída a partir de um conjunto de blocos denominados recursos (MILLS et al., 2002 apud FLEURY; FLEURY 2007, p. 15).

As competências organizacionais estão relacionadas àquelas que a empresa possui e, portanto, depende não somente das pessoas, mas da gestão que utiliza e da tecnologia que a suporta. Significa que a empresa para possuir determinada competência deve buscar uma sintonia das dimensões processos, tecnologia e pessoas, no sentido de formar e manter uma determinada competência organizacional reconhecida pelos seus stakeholders, quais sejam: clientes, fornecedores, acionistas, sociedade, concorrentes e empregados (FLEURY; FLEURY, 2001). 
As competências organizacionais estão associadas com a imagem da empresa, portanto, ao fazer a adequada gestão dos seus processos, das tecnologias que dispõe e dos talentos que possui, a empresa desenvolverá competências que irão fortalecer a sua imagem junto ao mercado ou junto à sociedade, no caso de empresas públicas ou sem fins lucrativos.

Portanto, a empresa deve ter além de funcionários talentosos, estratégias para viabilizar o uso adequado desses talentos, utilizando assim os seus recursos, alinhados dentro de um modelo de gestão que facilitará atingir os objetivos estratégicos da organização.

Segundo Rabechini Júnior e Carvalho (2003), as competências organizacionais referem-se à possibilidade de indivíduos ou equipes conduzirem seus projetos de forma a alcançarem os objetivos propostos, dando maior competitividade às empresas.

É de suma relevância que a harmonia entre as dimensões Gestão de Processos, Pessoas e Tecnologia exista para que a empresa obtenha sucesso a partir das suas competências organizacionais.

Para Fleury e Fleury (2001, p. 18).

As organizações que construírem competências fortes estão preparadas
para levar vantagem das oportunidades estratégicas positivas decorrentes
do poder de mercado. Em outras palavras, provavelmente, ganharão
vantagens competitivas importantes que produzirão poder de mercado
significativo. Essas organizações podem estar em condições de maior
controle sobre seus ambientes e, assim, de melhorar a redução das
incertezas. As organizações mas fracas serão forçadas a adaptarem-se
para fortalecerem suas habilidades de aprender e transformar esta
aprendizagem em competências.

Para Robbins (2002), a identificação das competências distintivas de uma organização é de suma importância, pois ela orientará as decisões sobre quais atividades são cruciais para o sucesso da organização. As competências distintivas definem aquilo que a empresa é capaz de fazer de modo superior a sua concorrência.

Para Hamel e Prahalad (1997), a organização que deseja ter bons resultados com as oportunidades de amanhã necessita conhecer, hoje, as competências essenciais que precisam ser desenvolvidas no futuro e poucas empresas sabem como alavancar essas competências existentes, rompendo as barreiras dos 
negócios atuais objetivando criar novo espaço competitivo. Os autores referem-se à competência como uma capacidade da organização de se tornar eficaz, com características difíceis de serem imitadas que possibilitem o acesso a diferentes mercados.

Ao definir sua estratégia competitiva, a empresa identifica as competências essenciais do negócio e as competências necessárias a cada função - as competências organizacionais. Dessa maneira, pode-se dizer que a organização possui diversas competências organizacionais, localizadas em diversas áreas. Dessas, apenas algumas são as competências essenciais, aquelas que a diferenciam e que lhe garantem uma vantagem competitiva sustentável perante as demais organizações.

Uma competência essencial não precisa necessariamente ser baseada em "tecnologia stricto senso". Pode estar associada ao domínio de qualquer estágio do ciclo de negócios, como, por exemplo, um profundo conhecimento das condições de operação de mercados específicos. Não obstante isso, para ser considerada uma competência essencial, esse conhecimento deve estar associado a um sistemático processo de aprendizagem, que envolve descobrimento/inovação e capacitação de pessoas (FLEURY; FLEURY, 2001).

"A evolução dessa estratégia competitiva vai depender, no longo prazo, da administração do processo de aprendizagem organizacional, que vai reforçar e promover as competências organizacionais e que vai dar foco e reposicionar as estratégias competitivas" (FLEURY; FLEURY, 2001).

Hamel e Prahalad (1997) destacam que somente através do desenvolvimento e estímulo de competências essenciais é que a alta gerência garantirá a continuidade do empreendimento. Elas são a fonte de desenvolvimento de futuros produtos.

Bruno-Faria e Brandão (2003) ressaltam que é possível classificar as competências como profissionais ou humanas, ou seja, aquelas relacionadas a indivíduos ou equipes de trabalho, e as organizacionais - aquelas inerentes à organização como um todo, ressaltando-se que as competências profissionais, aliadas a outros recursos dão origem as competências organizacionais. 
Dessa forma, as competências organizacionais são o resultado da interação das competências individuais e dos demais recursos que a organização dispõe que, acabam por agregar um somatório de conhecimentos, habilidades e atitudes, superior e até diferente do somatório das competências individuais dos componentes de determinadas organizações (BRUNO-FARIA; BRANDÃO, 2003).

O uso do modelo de competências permite o surgimento de uma gestão de pessoas mais alinhada com as expectativas e necessidades das organizações e das pessoas, trazendo ganhos para ambas.

\subsection{Processo de mapeamento de competências organizacionais}

O mapeamento de competências tem por objetivo identificar o gap (lacuna) de competências da empresa, conforme mostra a Figura 3. Esse processo (modelo) sugerido por lenaga (1978 apud BRANDÃO; BAHRY, 2005) consiste em estabelecer os objetivos e metas a serem alcançados pela organização para posteriormente identificar as lacunas entre as competências necessárias à consecução desses objetivos e as competências internas disponíveis na organização.

Visão dinâmica

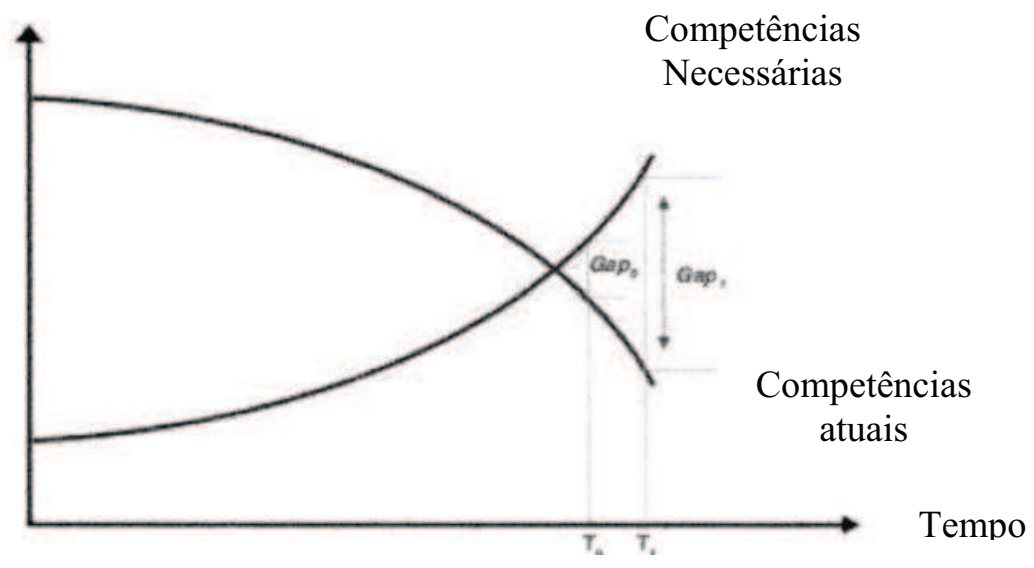

Figura 3: Identificação da lacuna (gap) de competência

Fonte: Adaptação de lenaga (1998 apud BRANDÃO; GUIMARÃES, 2001, p. 11)

Guimarães et al. (2001 apud BRANDÃO; GUIMARÃES, 2003) construíram um modelo de gestão de desempenho com base nas competências que implica na gestão da organização em planejar, selecionar, desenvolver e remunerar as pessoas, com ênfase nas competências essenciais das organizações e dos 
indivíduos. A essência desse modelo consiste em identificar as competências necessárias à concretização da visão de futuro da organização e, então, elaborar um mapeamento de competências internas.

Essa visão mostra o rumo desejado, o futuro estratégico da empresa e serve de orientação para políticas e práticas para reduzir ao mínimo o gap entre as competências existentes e aquelas necessárias ao cumprimento dos objetivos e metas organizacionais, conforme ilustra a Figura 4.

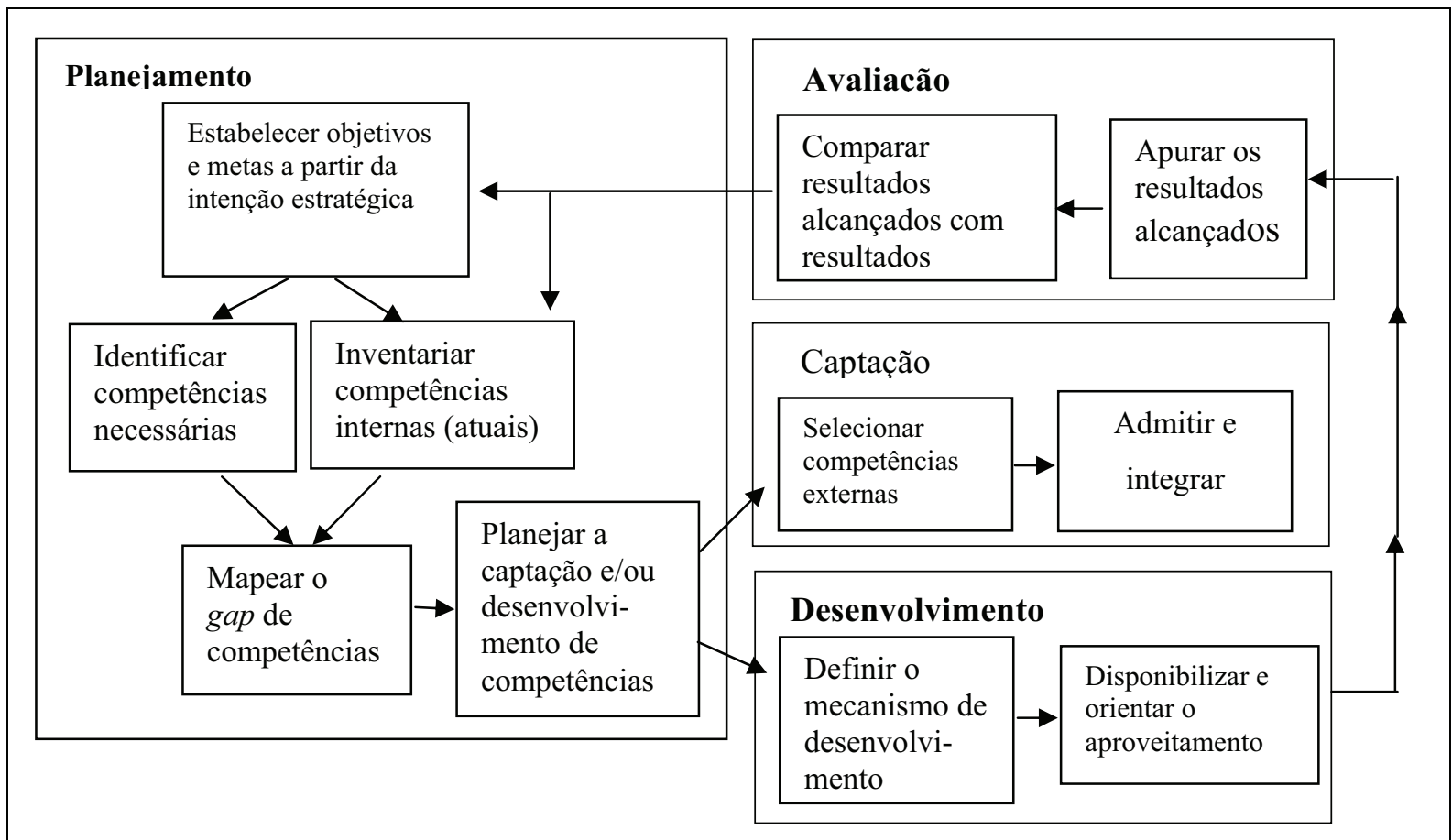

Figura 4: Identificação da lacuna (gap) de competência

Fonte: Adaptação de lenaga (1998 apud BRANDÃO; GUIMARÃES, 2001, p. 64)

Ao analisar a Figura 4, percebe-se que os esforços de planejamento, captação, desenvolvimento e avaliação de competências não ocorrem unicamente em nível individual, mas em todos os níveis organizacionais, pois as competências pessoais aliadas aos demais recursos dão origem à sustentação e à competência organizacional. Nesse processo, verifica-se que há certo nível de competitividade entre o cenário atual e o futuro da organização, o que garante a continuidade da sustentabilidade. A gestão por competência é um processo sistêmico, envolvendo diversos níveis da organização, o que exige uma visão estratégica organizacional.

Brandão e Guimarães (2001), ao tratarem da gestão de competências e gestão de desempenho, constataram que o conceito da competência é associado à ação e concluíram que não é possível tratar da gestão de competências sem 
considerar a gestão de desempenho, uma vez que a competência representa o próprio desempenho e este representa uma manifestação da competência.

A gestão de competência e a gestão de desempenho são tecnologias distintas que representam instrumentos que se complementam em um contexto mais amplo de gestão organizacional. Esse contexto integra em um único modelo de gestão às atividades de planejamento, acompanhamento e avaliação de desempenho, a partir de um mapeamento de competências desde o nível da organização até o individual, como sugerido por Guimarães et al. (2001 apud BRUNO-FARIA; BRANDÃO, 2003), conforme ilustra a Figura 5.

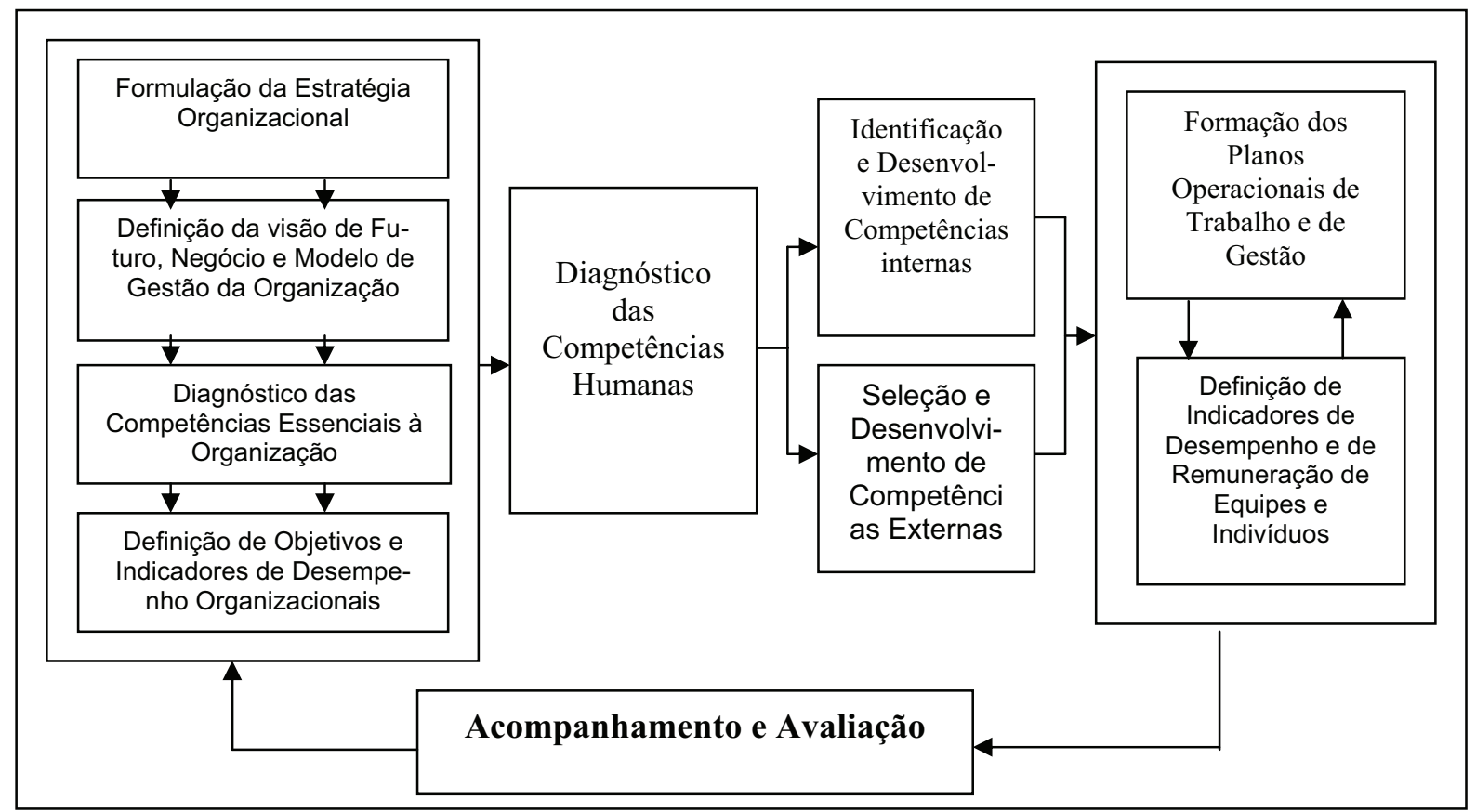

Figura 5: Modelo de gestão de desempenho baseado nas competências

Fonte: Adaptado de Guimarães et al. (2001 apud BRUNO-FARIA; BRANDÃO, 2003, p. 38 )

Carbone et al. (2006) destacam que normalmente para essa identificação, primeiro realiza-se uma pesquisa documental que inclui a análise do conteúdo da missão, da visão de futuro, dos objetivos e de outros documentos relativos à estratégia organizacional.

Em seguida, realiza-se a coleta de dados com pessoas-chave da organização para que tais dados sejam cotejados com a análise documental, conforme proposto por Bruno-Faria e Brandão (2003).

Dessa forma, tem-se uma visão das competências que, uma vez desenvolvidas, passam a influenciar a organização com relação a novas estratégias. 
A seguir, encontra-se descrita a metodologia de pesquisa empregada no presente estudo. 


\section{METODOLOGIA}

Segundo Vergara (2000) é de fundamental importância para uma pesquisa empírica que o pesquisador informe o que se pretende investigar e o porquê de tal pesquisa. Também apresentar conceitos e descrever a população, amostra e seleção dos sujeitos dentre outros aspectos relacionados ao desenho de pesquisa.

Pretende-se neste item descrever a metodologia bem como as técnicas de pesquisa adotadas no mapeamento das competências fundamentais a um hospital universitário e suas principais unidades.

A seguir, são apresentados os aspectos metodológicos do presente trabalho o que inclui o tipo de pesquisa, participantes da pesquisa, instrumento, procedimentos e análise de dados.

\subsection{Tipo de pesquisa}

Adotou-se a técnica de entrevista semi-estruturada individual, tendo em vista a natureza pessoal e reservada do assunto tratado e que, dado objetivo do estudo, pretendeu-se maximizar a oportunidade de compreender as diferentes percepções dos entrevistados sobre as principais competências da organização (GASKELL, 2002).

O estudo compreendeu duas etapas de coleta de dados. Na primeira, foi realizada pesquisa qualitativa através de entrevistas semi-estruturadas com 0 objetivo de identificar as competências organizacionais do HUB. O método qualitativo, diferentemente do quantitativo que busca numerar ou medir unidades ou categorias, não emprega um instrumento estatístico, fazendo uso de amostras não probabilísticas (GIL, 1994), ou seja, o critério de determinação da amostra não é estatístico, mas depende unicamente dos critérios estabelecidos pelo pesquisador. É o método ideal para o estudo da natureza de fenômenos sociais (aprofundar o como), em situações onde se busca substituir uma simples informação estatística por dados qualitativos e quando se pretende compreender aspectos psicológicos ou indicadores de funcionamento de estruturas sociais.

Na segunda etapa, foi realizada uma pesquisa quantitativa a partir do uso de um questionário para verificar a percepção dos servidores da Instituição quanto ao grau de importância e de domínio das competências organizacionais para, em 
seguida, identificar o grau de prioridade de investimento de ações educacionais para desenvolver as competências organizacionais.

Foi utilizada, também, pesquisa documental que, segundo Vergara (2000), visa obter elementos sobre o contexto de produção dos serviços na organização.

\subsection{Amostra de documentos e participantes da pesquisa}

\subsubsection{Amostra de documentos}

Para a pesquisa documental foram utilizados: regimento interno do Hospital e relatórios elaborados pelos dirigentes da Instituição que retratam a missão, estratégias, valores, processos e aspectos da cultura da organização.

\subsubsection{Participantes da pesquisa}

A pesquisa objeto deste trabalho foi realizada no Hospital Universitário de Brasília (HUB). A escolha da Organização teve como critério, além da sua importância para a área da saúde, a facilidade de obtenção dos dados devido à praticidade de contato das pesquisadoras com a Instituição. A realização da pesquisa foi precedida de autorização da Organização.

A pesquisa foi feita em duas etapas. Na primeira, foram entrevistados quatro Diretores das principais áreas do HUB. Na segunda etapa, foi aplicado questionário para 18 chefes de Divisão, ligados diretamente a estas quatro Diretorias.

Esses profissionais foram selecionados porque possuíam maior conhecimento da estratégia, da missão, dos valores, dos processos e da cultura da organização, uma vez que atuavam como Diretores e Chefes das diferentes áreas do HUB.

\subsection{Instrumento}

O roteiro das entrevistas iniciais incluía questões que permitissem identificar as Competências Organizacionais do HUB e das principais Unidades. 
As informações para identificar as competências foram coletadas por meio de entrevistas individuais, semi-estruturadas, a partir de um roteiro, conforme Apêndice A.

As competências identificadas nas entrevistas compuseram o questionário aplicado na segunda etapa da pesquisa. O questionário composto por itens que expressavam competências organizacionais e dados demográficos foi respondido em duas escalas do tipo Likert, que ia de 1 a 5 para avaliar grau de importância e grau de domínio. O índice de importância variava de sem importância a extrema importância e o índice de domínio variando de sem domínio a total domínio (vide Apêndice B).

\subsection{Procedimentos}

Antes de entrevistar os diretores, foi realizada uma entrevista teste com um chefe de divisão do hospital, que permitiu ajustar o roteiro da entrevista.

Após alguns comentários introdutórios sobre o objetivo da pesquisa, foi feito um pedido para gravar as entrevistas. Ao iniciar a entrevista foi apresentado a cada diretor entrevistado o conceito de competência organizacional, de Bruno-Faria e Brandão (2003, p. 54) como sendo "atributo subjacente à organização, que lhe permite atingir seus objetivos estratégicos", tendo como exemplo de competência organizacional responsável pela promoção de ações de Treinamento, Desenvolvimento e Educação (TD\&E) para servidores públicos (BRUNO-FARIA; BRANDÃO, 2003, p. 42).

Os questionários foram distribuídos entre os chefes de Divisão. Foi entregue diretamente a cada um em seu próprio local de trabalho. Após a entrega do questionário foram feitos alguns comentários sobre o objetivo do trabalho, agradecendo a colaboração do entrevistado.

\subsection{Análise das informações}

A análise das entrevistas foi realizada com o emprego da técnica de análise de conteúdo (FRANCO, 2003). 
Para análise dos questionários, foram calculadas médias e desvio padrão dos índices de importância e do índice do domínio de cada competência constante no questionário.

Para cálculo do índice de prioridade, multiplicou-se os resultados da escala de importância pelo inverso da escala de domínio. Assim, quanto mais importante uma competência e menor o domínio por parte da Instituição, maior a prioridade.

Vale ressaltar que os resultados de médias de prioridades poderiam variar entre 1,00 (nenhuma prioridade) a 25,00 (prioridade extrema). Uma vez que o ponto médio das escalas eram iguais a 3, as médias de prioridades iguais ou superior a 9 merecem a atenção da Instituição. 


\section{RESULTADOS E DISCUSSÃO}

Os resultados aqui apresentados foram obtidos a partir das entrevistas individuais com os principais diretores do HUB e aplicação de questionários junto aos chefes de suas principais unidades, que resultou no mapeamento das principais competências da Instituição e de suas unidades centrais na percepção dessas pessoas.

Inicialmente, são apresentadas as características centrais da organização, dos participantes das entrevistas e dos respondentes dos questionários.

Em seguida, são descritas os resultados referentes às competências.

\subsection{Caracterização da Instituição e dos Participantes da Pesquisa}

\subsubsection{HUB e Diretorias}

O Hospital Universitário de Brasília (HUB), integrante da rede de hospitais universitários do MEC, teve o seu funcionamento autorizado pelo Decreto $\mathrm{n}^{\circ} 70178$, de 21 de fevereiro de 1972.

A origem do HUB foi o Instituto de Pensão e Aposentadoria dos Servidores do Estado (IPASE). Foi inaugurado em agosto de 1972 pelo então Presidente General Emilio Garastazu Médici, era conhecido como Hospital dos Servidores da União (HSU), que atendia apenas os servidores públicos federais.

$\mathrm{Na}$ sua inauguração recebeu o nome de Hospital do Distrito Federal Presidente Médici (HDFPM). Ainda na década de 70, extinto o IPASE, o Hospital passou a fazer parte do INAMPS. Mudou de nome algumas vezes até ser reconhecido pelo MEC como Hospital Universitário. Finalmente em 1999 foi cedido à UnB, passando a se chamar Hospital Universitário de Brasília (HUB).

O HUB iniciou suas atividades com 240 leitos, com um serviço de Pronto Atendimento onde agregavam diversas especialidades: pediatria, clinica cirúrgica, clinica médica, terapia intensiva, unidade de radiologia, unidade de medicina física e de Reabilitação. Existiam 34 salas de ambulatórios.

Desde então, as atividades de ensino, pesquisa e extensão passaram a representar o grande diferencial do Hospital em relação aos demais hospitais da 
cidade, e com o compromisso principal de formar novos profissionais da área de saúde (médicos, enfermeiros, dentistas, nutricionistas, farmacêuticos), indissoluvelmente ligado ao atendimento à população e à produção de conhecimento e desenvolvimento de novas tecnologias, adaptadas às características e exigências de nossa sociedade.

Além de receber os alunos de graduação dos diferentes cursos da UnB (Medicina, Enfermagem, Odontologia, Nutrição, Farmácia, Psicologia, Serviço Social, Administração, Educação, Arquitetura, dentre outras), o HUB oferece estágios de pós-graduação e de nível médio em diferentes áreas.

A Residência médica é uma das mais completas do Distrito Federal, contando com 20 programas credenciados pelo MEC e 78 médicos residentes.

O HUB conta atualmente com 289 leitos e 121 salas de ambulatório. Seu corpo clínico é formado por diversos profissionais da área de saúde: professores da UnB, servidores FUB e do Ministério da Saúde e profissionais contratados. Serve à comunidade do Distrito Federal e das cidades do entorno de Brasília, bem como de várias outras Unidades da Federação, sendo, portanto um hospital de referência onde é desenvolvido um importante trabalho de ensino, pesquisa e assistência.

Na Figura 6 é apresentado o Organograma do HUB. 


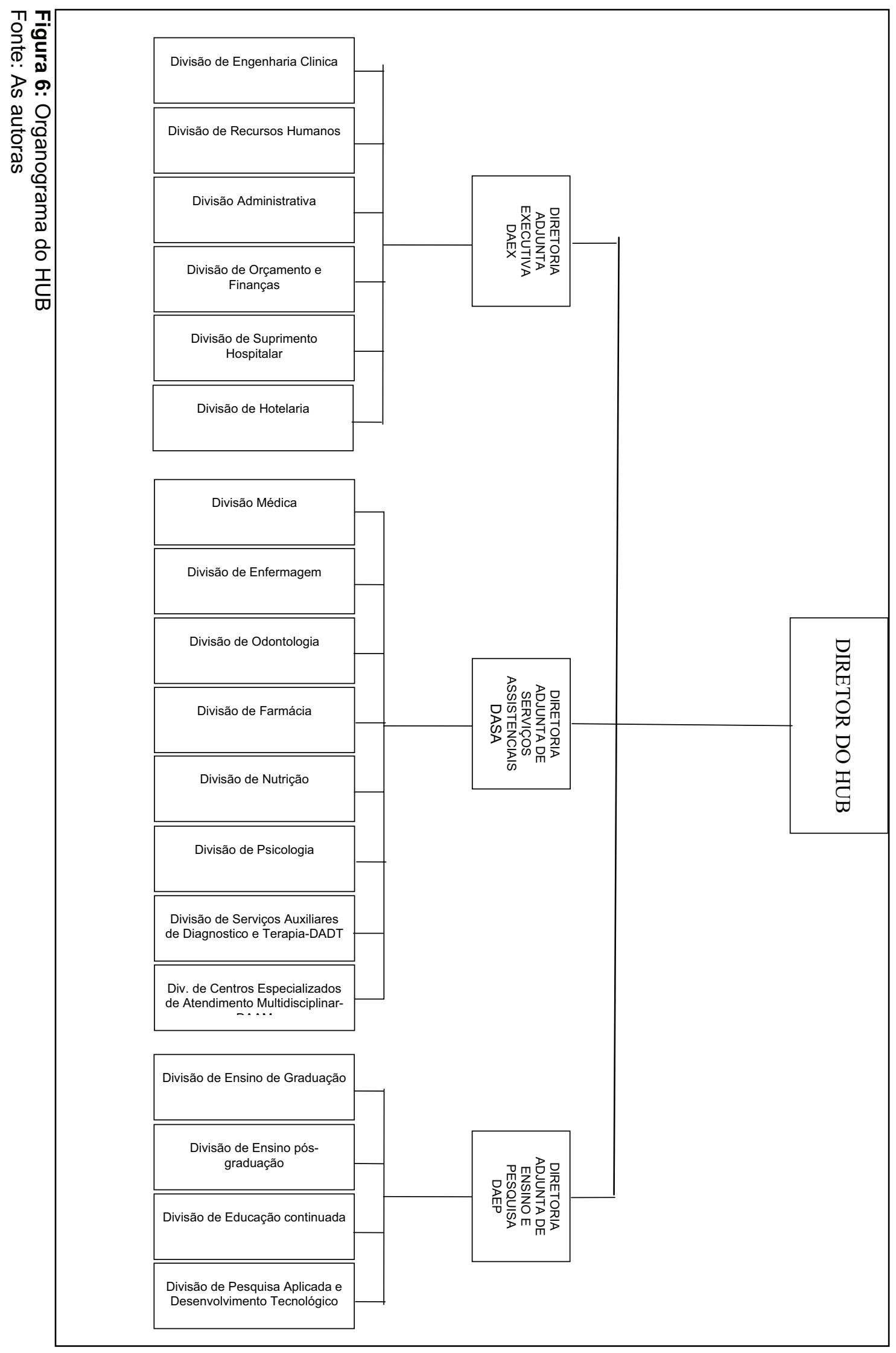




\subsubsection{Participantes das entrevistas}

Foram entrevistados o diretor geral e os três diretores adjuntos da Organização, dos quais dois são do sexo masculino e dois do sexo feminino, com idade variando entre 41 e 65 anos. No que se refere à formação, dois possuem doutorado e dois especialização. Quanto ao tempo de trabalho na Organização variava entre 8 e 32 anos.

\subsubsection{Respondentes dos Questionários}

Foram encaminhados 18 questionários aos chefes de divisão. Todos foram devolvidos, uma vez que um dos chefes era responsável por duas divisões, o total correspondeu a 17. A idade média dos respondentes era de 47 anos; sete são do sexo masculino e dez do sexo feminino. O tempo médio de trabalho na Organização era de 12 anos. No tocante à escolaridade cinco tinham doutorado, três mestrado, cinco especialização, dois com curso superior completo e dois com segundo grau completo.

\subsection{Definição das competências organizacionais do HUB e Diretorias}

A partir da análise de conteúdo das entrevistas foram identificadas as competências com suas respectivas definições operacionais. Para cada competência foi incluído um trecho da verbalização dos sujeitos como forma de ilustrar tal resultado.

\section{Competências da HUB}

\section{Prestar serviço de alta complexidade na área de saúde.}

Conjunto de procedimentos que envolvem alta tecnologia e alto custo, objetivando propiciar à população acesso a serviços qualificados.

Exemplo: "A competência que se deveria desenvolver é dar mais atenção, dar maior complexidade ao serviço de saúde". "Criar um cenário pra ensino na prática dentro de uma oferta de assistência à saúde de alta complexidade".

Formar profissionais na área de saúde para atuação futura no mercado de trabalho.

Competência que engloba os conhecimentos, metodologias e técnicas relacionadas 
com o processo de transmissão do conhecimento, visando a formação de profissionais altamente qualificados.

Exemplo: "Nós entendemos que o Hospital precisa formar profissionais altamente qualificados. Aqueles profissionais que dependem de uma estrutura complexa como um hospital pra sua formação".

\section{Criar conhecimento}

Capacidade de desenvolver pesquisa tendo como principal meta a geração de novos conhecimentos.

Exemplo: "...Além disso o Hospital tem a obrigação de criar conhecimento...".

\section{Prestar atendimento a públicos diferenciados.}

Habilidade para interagir com pessoas de diferentes classes sociais e pessoas com diferentes problemas de forma empática, inclusive diante de situações conflitantes, demonstrando atitudes assertivas, respeitosa, comportamento maduro e não combativos.

Exemplo: "Dentro desse atendimento de um público diferenciado na minha visão ele tem que ter a primeira coisa fundamental é saber lidar com pessoas, talvez uma necessidade dentro do nosso ambiente de trabalho seja a educação para te mudar no sentido de manter a sensibilidade no atendimento ao público".

\section{Difundir nova cultura de humanização}

Divulgar a humanização como algo fundamental na assistência do indivíduo, no processo de reabilitação, pois é o esforço de tratar as pessoas, respeitando suas particularidades, sabendo escutar e compreender, sem afetar a dignidade de cada um.

Exemplo: "Na minha opinião é cuidar do ensino, é cuidar da formação do profissional não esquecendo da parte assistencial, difundindo uma cultura humanizada".

\section{Prestar assistência altamente qualificada e de alta qualidade.}

Capacidade de implementar novas tecnologias adquiridas por meio de pesquisas conferindo relevância ao conteúdo dos conhecimentos que serão revertidos em prol da assistência na saúde, prestando, assim, um atendimento de alta qualidade e altamente qualificado. 
Exemplo: "O papel do Hospital Universitário é fazer assistência,... fazer uma assistência diferenciada, altamente qualificada".

\section{Competências da DAEX}

\section{Propiciar a infra-estrutura essencial ao funcionamento do Hospital.}

Conhecimento e capacidade de utilização dos recursos disponíveis, a fim de que outros serviços disponha dos recursos necessários para cumprir bem suas tarefas. Gerencia recursos e define prioridades.

Exemplo: "Ela é a facilitadora administrativa das coisas". "A DAEX cuida do suporte técnico para que as outras coisas sejam desenvolvidas". "É de responsabilidade da DAEX, desde a segurança até a manutenção de equipamentos, folha de pagamento, engenharia clinica..." "Essa diretoria tem que atender todas as demandas referentes ao ensino e referentes à assistência".

Planejar e coordenar as atividades técnicas, administrativas e financeiras do HUB.

Capacidade de planejamento e coordenação nas áreas de procedimentos técnicos, administrativos e financeiros da organização.

Exemplo: "Cuida do suporte técnico, administrativo e financeiro para que as outras atividades sejam desenvolvidas ".

\section{Competências da DASA}

\section{Oferecer as condições para a prestação de atendimento aos pacientes.}

Conjunto de políticas e práticas com o intuito de oferecer condições para o atendimento ao paciente, bem como para o desenvolvimento das atividades docentes. Busca resultados integrando pessoas e recursos existentes.

Exemplo: "Tem que ter uma visão muito mais abrangente. Visão do atendimento ao paciente de ambulatório, pronto socorro, enfermaria..." "É a diretoria que cuida de toda a assistência".

Oferecer as condições para o desenvolvimento de atividade de ensino e pesquisa com qualidade.

Competência para oferecer treinamentos e estudos no intuito da busca do conhecimento para melhorar os trabalhos desenvolvidos na organização. 
Exemplo: "A DASA tem uma interface com as outras diretorias adjuntas, oferecendo condições para que desenvolvam seus trabalhos..."

\section{Competências da DAEP}

Planejar e coordenar atividades de ensino e pesquisa.

Capacidade de organizar, estruturar e supervisionar previamente as atividades docentes, considerando as demandas.

Exemplo: "A DAEP tem que supervisionar e planejar dois pontos importantes: primeiro o ensino de graduação e depois o ensino de pós-graduação".

\section{Normatizar as ações de ensino e pesquisa no HUB.}

Domínio do conteúdo relacionado às normas, regulamentos, leis, decretos e outros atos normativos relacionados à organização.

Exemplo: “...o de educação continuada, é aquele que está fazendo curso de especialização, estágios, toda essa parte de normatização dentro do hospital fica nessa parte ..."

Incentivar e promover o desenvolvimento das atividades de pesquisa e de extensão no HUB.

Domínio para incentivar pesquisas que busquem melhorar o trabalho desenvolvido pela organização.

Exemplo: "o da educação continuada, promovendo curso de especialização, estágios, os cursos de formação específica, formando mestrandos, doutorandos para que as pessoas adquira competência completa".

Essas competências fizeram parte do questionário (Apêndice B) cujos resultados se encontram a seguir.

\subsection{Graus de importância, domínio e prioridade das competências organizacionais do HUB e Diretorias}

Para cada competência da organização e de suas principais diretorias foram calculados a média e o desvio padrão da importância e grau de domínio das 
competências. Em seguida, foi calculada a prioridade para efeito de verificação da necessidade de investimentos em ações de melhoria.

A Tabela 1 apresenta a tabulação do grau de importância das competências organizacionais do HUB.

Tabela 1 - Graus de importância das competências organizacionais do HUB

\begin{tabular}{l|l|l}
\hline \multicolumn{1}{c|}{ Competências } & Média & $\begin{array}{l}\text { Desvio } \\
\text { Padrão }\end{array}$ \\
\hline $\begin{array}{l}\text { Formação de profissionais na área de saúde para atuação futura no } \\
\text { mercado de trabalho. }\end{array}$ & 4,82 & 0,39 \\
\hline Prestar serviço de alta complexidade na área de saúde. & 4,76 & 0,75 \\
\hline Ser capaz de criar conhecimento. & 4,59 & 0,62 \\
\hline $\begin{array}{l}\text { Ser capaz de fazer assistência altamente qualificada e de alta } \\
\text { qualidade. }\end{array}$ & 4,53 & 0,87 \\
\hline Difundir nova cultura de humanização. & 4,50 & 0,82 \\
\hline Ser capaz de prestar atendimento a públicos diferenciados. & 4,44 & 1,03 \\
\hline
\end{tabular}

A Tabela 1 indica que todas as competências apresentam um elevado grau de importância, com destaque para a competência referente à formação de profissionais na área de saúde para atuação futura no mercado de trabalho que, se situou próximo ao grau de extrema importância (5 = extrema importância).

Os graus de domínio das competências organizacionais do HUB são apresentados na Tabela 2.

Tabela 2 - Graus de domínio das competências organizacionais do HUB

\begin{tabular}{l|l|l}
\hline \multicolumn{1}{c|}{ Competências } & Média & $\begin{array}{l}\text { Desvio } \\
\text { Padrão }\end{array}$ \\
\hline $\begin{array}{l}\text { Formação de profissionais na área de saúde para atuação futura no } \\
\text { mercado de trabalho. }\end{array}$ & 4,47 & 0,72 \\
\hline Ser capaz de criar conhecimento. & 3,88 & 0,78 \\
\hline Prestar serviço de alta complexidade na área de saúde. & 3,65 & 0,99 \\
\hline $\begin{array}{l}\text { Ser capaz de fazer assistência altamente qualificada e de alta } \\
\text { qualidade. }\end{array}$ & 3,59 & 1,00 \\
\hline Ser capaz de prestar atendimento a públicos diferenciados. & 3,50 & 1,03 \\
\hline Difundir nova cultura de humanização. & 2,81 & 0,98 \\
\hline
\end{tabular}

Verifica-se que o grau de domínio das competências oscila entre médio e muito domínio, segundo a escala que variava de 1 a 5 . Observa-se que o grau de domínio referente a difundir nova cultura de humanização é visto pelos respondentes entre pouco e médio domínio, merecendo ações de investimento por parte da organização. 
Por outro lado, a competência referente à "formação de profissionais na área de saúde para atuação futura no mercado de trabalho", foi percebida pelos respondentes como, tendo muito domínio.

A seguir, para efeito de investimentos em ações organizacionais diversas, tais como treinamento e desenvolvimento, foi calculado o índice de prioridade a ser atribuída pela Instituição. Para o cálculo da prioridade, multiplicou-se os resultados da escala de importância pelo inverso da escala de domínio. Assim, quanto mais importante uma competência e menor o domínio por parte da Instituição, maior a prioridade.

Para melhor entender a Tabela 3, vale ressaltar que os resultados de médias de prioridades poderiam variar entre 1,00 (nenhuma prioridade) a 25,00 (prioridade extrema). Uma vez que o ponto médio das escalas eram iguais a 3 , as médias de prioridades iguais ou superior a 9 merecem a atenção da Instituição.

$\mathrm{Na}$ Tabela 3, são apresentados os resultados em ordem decrescente de prioridade.

Tabela 3 - Graus de prioridade das competências organizacionais do HUB

\begin{tabular}{|c|c|c|}
\hline Competências & Média & $\begin{array}{l}\text { Desvio } \\
\text { Padrão }\end{array}$ \\
\hline Difundir nova cultura de humanização. & 14,06 & 4,46 \\
\hline Prestar serviço de alta complexidade na área de saúde. & 10,82 & 4,17 \\
\hline Ser capaz de prestar atendimento a públicos diferenciados. & 10,56 & 4,40 \\
\hline $\begin{array}{l}\text { Ser capaz de fazer assistência altamente qualificada e de alta } \\
\text { qualidade. }\end{array}$ & 10,53 & 4,26 \\
\hline Ser capaz de criar conhecimento. & 9,59 & 3,54 \\
\hline $\begin{array}{l}\text { Formação de profissionais na área de saúde para atuação futura no } \\
\text { mercado de trabalho. }\end{array}$ & 7,29 & 3,25 \\
\hline
\end{tabular}

Difundir nova cultura de humanização aparece no topo como maior índice de prioridade, enquanto que a formação de profissionais na área de saúde para atuação futura no mercado de trabalho aparece como menos prioritária demonstrando que a Organização tem elevado domínio no tocante a essa competência.

A seguir, serão descritos os resultados referentes a cada Diretoria do HUB.

A Tabela 4 apresenta os graus de importância das competências organizacionais da DAEX. 
Tabela 4 - Graus de importância das competências organizacionais da DAEX

\begin{tabular}{l|l|l}
\hline \multicolumn{1}{c|}{ Competências } & Média & \multicolumn{1}{c}{$\begin{array}{l}\text { Desvio } \\
\text { Padrão }\end{array}$} \\
\hline $\begin{array}{l}\text { Planejar e coordenar as atividades técnicas, administrativas e } \\
\text { financeiras do HUB. }\end{array}$ & 4,81 & 0,54 \\
\hline Propiciar a infra-estrutura essencial ao funcionamento do Hospital. & 4,71 & 0,59 \\
\hline
\end{tabular}

Os resultados demonstram que as atividades de planejar e coordenar as atividades técnicas, administrativas e financeiras, bem com propiciar a intra-estrutura essencial ao funcionamento do Hospital foram consideradas entre muita e extrema importância para a DAEX.

Os graus de domínio das competências organizacionais da DAEX são apresentados na Tabela 5.

Tabela 5 - Graus de domínio das competências organizacionais da DAEX

\begin{tabular}{l|l|l}
\hline \multicolumn{1}{c|}{ Competências } & Média & $\begin{array}{l}\text { Desvio } \\
\text { Padrão }\end{array}$ \\
\hline Propiciar a infra-estrutura essencial ao funcionamento do Hospital. & 3,24 & 0,83 \\
\hline $\begin{array}{l}\text { Planejar e coordenar as atividades técnicas, administrativas e } \\
\text { financeiras do HUB. }\end{array}$ & 3,38 & 1,20 \\
\hline
\end{tabular}

Os resultados mostram que o grau de domínio das competências está em um nível mediano ( 3 = médio domínio). da DAEX.

Na Tabela 6 serão descritas as prioridades das competências organizacionais

Tabela 6 - Graus de prioridade das competências organizacionais da DAEX

\begin{tabular}{l|l|l}
\multicolumn{1}{c|}{ Competências } & Média & $\begin{array}{l}\text { Desvio } \\
\text { Padrão }\end{array}$ \\
\hline Propiciar a infra-estrutura essencial ao funcionamento do Hospital. & 12,94 & 4,13 \\
\hline $\begin{array}{l}\text { Planejar e coordenar as atividades técnicas, administrativas e } \\
\text { financeiras do HUB. }\end{array}$ & 12,44 & 5,51 \\
\hline
\end{tabular}

Dentre os principais aspectos questionados verifica-se que propiciar a infraestrutura essencial ao funcionamento do hospital e planejar e coordenar as atividades técnicas, administrativas e financeira do HUB são consideradas competências de maior relevância nessa Divisão, o que exige especialização funcional e ações governamentais.

A Tabela 7 demonstra os graus de importância das competências da DASA. 
Tabela 7 - Graus de importância das competências organizacionais da DASA

\begin{tabular}{l|l|l}
\multicolumn{1}{c|}{ Competências } & Média & $\begin{array}{l}\text { Desvio } \\
\text { Padrão }\end{array}$ \\
\hline $\begin{array}{l}\text { Oferecer as condições para a prestação de atendimento aos } \\
\text { pacientes. }\end{array}$ & 4,69 & 0,60 \\
\hline $\begin{array}{l}\text { Oferecer as condições para o desenvolvimento de atividade de } \\
\text { ensino e pesquisa com qualidade. }\end{array}$ & 4,69 & 0,70 \\
\hline
\end{tabular}

Os resultados demonstram que os respondentes consideram as competências com o mesmo grau de importância, entre muita e extrema importância.

Os graus de domínio das competências organizacionais da DASA são apresentados na Tabela 8.

Tabela 8 - Graus de domínio das competências organizacionais da DASA

\begin{tabular}{l|l|l}
\hline \multicolumn{1}{c|}{ Competências } & Média & \multicolumn{1}{c}{$\begin{array}{l}\text { Desvio } \\
\text { Padrão }\end{array}$} \\
\hline $\begin{array}{l}\text { Oferecer as condições para a prestação de atendimento aos } \\
\text { pacientes. }\end{array}$ & 3,62 & 0,96 \\
$\begin{array}{l}\text { Oferecer as condições para o desenvolvimento de atividade de } \\
\text { ensino e pesquisa com qualidade. }\end{array}$ & 3,62 & 0,88 \\
\hline
\end{tabular}

Os resultados mostram que o grau de domínio das competências é mediano (entre 3 = médio domínio e 4 = muito domínio), embora estando acima do ponto médio da escala é importante que a organização desenvolva políticas de investimento na organização.

$\mathrm{Na}$ Tabela 9 são apresentados os graus de prioridade das competências organizacionais da DASA.

Tabela 9 - Graus de prioridade das competências organizacionais da DASA

\begin{tabular}{l|l|l}
\multicolumn{1}{c|}{ Competências } & Média & $\begin{array}{l}\text { Desvio } \\
\text { Padrão }\end{array}$ \\
\hline $\begin{array}{l}\text { Oferecer as condições para a prestação de atendimento aos } \\
\text { pacientes. }\end{array}$ & 11,00 & 4,08 \\
\hline $\begin{array}{l}\text { Oferecer as condições para o desenvolvimento de atividade de } \\
\text { ensino e pesquisa com qualidade. }\end{array}$ & 10,75 & 3,19 \\
\hline
\end{tabular}

Os resultados indicam maior grau de prioridade para oferecer as condições para a prestação de atendimento aos pacientes, embora a organização considere que as condições para o desenvolvimento de atividade de ensino e pesquisa com qualidade, também aparece com alto grau de competência.

A Tabela 10 aborda os graus de importância das competências da DAEP. 
Tabela 10 - Graus de importância das competências organizacionais da DAEP

\begin{tabular}{l|l|l}
\multicolumn{1}{c|}{ Competências } & Média & \multicolumn{1}{c}{$\begin{array}{l}\text { Desvio } \\
\text { Padrão }\end{array}$} \\
\hline Normatizar as ações de ensino e pesquisa no HUB. & 4,80 & 0,56 \\
\hline $\begin{array}{l}\text { Incentivar e promover o desenvolvimento das atividades de pesquisa } \\
\text { e de extensão no HUB. }\end{array}$ & 4,62 & 0,62 \\
\hline Planejar e coordenar atividades de ensino e pesquisa. & 4,56 & 1,08 \\
\hline
\end{tabular}

As análises mostram que normatizar as ações de ensino e pesquisa é de maior importância (entre $4=$ muita importância e $5=$ extrema importância) na organização, o que não torna menos relevante 0 incentivo e promoção do desenvolvimento das atividades de pesquisa e de extensão da HUB, bem como o planejamento e coordenação das atividades de ensino e pesquisa.

A Tabela 11 apresenta os graus de domínio das competências organizacionais da DAEP.

Tabela 11 - Graus de domínio das competências organizacionais da DAEP

\begin{tabular}{l|l|l}
\multicolumn{1}{c|}{ Competências } & Média & \multicolumn{1}{c}{$\begin{array}{l}\text { Desvio } \\
\text { Padrão }\end{array}$} \\
\hline Normatizar as ações de ensino e pesquisa no HUB. & 3,81 & 0,91 \\
\hline Planejar e coordenar atividades de ensino e pesquisa. & 3,67 & 1,11 \\
\hline $\begin{array}{l}\text { Incentivar e promover o desenvolvimento das atividades de pesquisa } \\
\text { e de extensão no HUB. }\end{array}$ & 3,62 & 0,88 \\
\hline
\end{tabular}

A DAEP demonstra maior domínio na normatização e ações de ensino e pesquisa e menor domínio no incentivo e promoção do desenvolvimento das atividades de pesquisa e extensão, resultados que merecem uma melhor atenção por parte da organização.

Na Tabela 12 são apresentados os graus de prioridades das competências organizacionais da DAEP.

Tabela 12 - Graus de prioridade das competências organizacionais da DAEP

\begin{tabular}{l|l|l}
\multicolumn{1}{c|}{ Competências } & Média & $\begin{array}{l}\text { Desvio } \\
\text { Padrão }\end{array}$ \\
\hline $\begin{array}{l}\text { Incentivar e promover o desenvolvimento das atividades de pesquisa } \\
\text { e de extensão no HUB. }\end{array}$ & 11,00 & 4,46 \\
\hline Normatizar as ações de ensino e pesquisa no HUB. & 10,00 & 3,85 \\
\hline Planejar e coordenar atividades de ensino e pesquisa. & 9,80 & 3,95 \\
\hline
\end{tabular}

As prioridades da DAEP são: o incentivo e promoção do desenvolvimento das atividades de pesquisa e extensão no HUB, seguida da normatização das ações de ensino e pesquisas e do planejamento e coordenação das atividades de ensino. 
Os resultados apresentados na pesquisa mostram que o HUB e suas divisões organizacionais, como órgão da Administração Pública estão relacionados ao Estado, conforme destacado por Meirelles (2000), que afirma que a administração pública apresenta estrutura e atividades relacionadas ao Estado, sobre a qual repousa toda a concepção moderna de organização e funcionamento dos serviços.

Em relação ao domínio das divisões percebe-se que o processo adotado está relacionado com a visão de lenaga (lenaga, 1978 apud BRANDÃO; BAHRY, 2005) que consiste em estabelecer os objetivos e metas a serem alcançados pela organização para posteriormente identificar as lacunas entre as competências necessárias a consecução desses objetivos e as competências internas disponíveis na organização.

Verifica-se, também, que os participantes consideram relevantes como competências, o planejamento, desenvolvimento e incentivo, condizendo com a visão de Guimarães et al. (2001 apud BRANDÃO; GUIMARÃES, 2003), os quais construíram um modelo de gestão de desempenho com base nas competências que implica na gestão da organização em planejar, selecionar, desenvolver e remunerar recursos humanos,

No HUB e suas divisões é possível perceber que as competências de cada setor são regidas por princípios norteadores da Administração Pública, que segundo Meirelles (2000) são: legalidade, finalidade, impessoalidade, publicidade e eficiência.

Vale destacar que difundir nova cultura de humanização; propiciar a infraestrutura ao funcionamento do Hospital; oferecer as condições para a prestação de atendimento aos pacientes $\mathrm{e}$; incentivar e promover o desenvolvimento das atividades de pesquisa e extensão no HUB são competências, tanto do HUB como das Diretorias, percebidas com maior índice de prioridade.

Contudo, foram apontadas como competências de menor índice de prioridade a formação de profissionais na área de saúde para atuação futura no mercado de trabalho; planejar e coordenar as atividades técnicas, administrativas e financeiras do HUB; oferecer as condições para o desenvolvimento de atividades de ensino e pesquisa com qualidade; e planejar e coordenar atividades de ensino e pesquisa. 
Finalmente, cabe ressaltar que não foi possível confrontar os resultados deste estudo com outras pesquisas, por não terem sido localizados estudos similares na literatura nacional. 


\section{CONCLUSÔES}

A gestão de competência é uma característica relevante diante dos desafios modernos. As mudanças exigem que se reconheça a necessidade de gestão organizacional para democratização das relações e transformações culturais.

A valorização do trabalho profissional e o estímulo ao desenvolvimento dos trabalhadores favorecem o desenvolvimento das competências organizacionais e, no caso do setor público, contribui para a melhoria do serviço prestado ao usuário.

A presente pesquisa teve como objetivo principal identificar as competências organizacionais de um hospital universitário e de suas principais unidades, portanto, a amostra limitou-se à diretoria geral, às três diretorias adjuntas e às 18 divisões. Não foi possível realizar um confronto com a visão dos demais funcionários das unidades, pelo curto tempo destinado à pesquisa. Estas limitações podem ser vistas como uma oportunidade para estudos futuros. Destaca-se também, como limitação, a pouca literatura sobre $o$ assunto.

Este estudo mostrou, a partir do mapeamento de competências organizacionais, o grau de importância e de domínio na visão dos participantes da pesquisa. Isto representa uma ferramenta fundamental na melhoria dos processos, a partir da identificação do índice de prioridade, podendo ser o caminho para o aperfeiçoamento da prestação de serviços ao usuário.

As competências identificadas possuem um elevado grau de importância, porém não são desenvolvidas o suficiente para que a Organização atinja suas estratégias. Destarte, embora os dirigentes avaliem as competências identificadas como muito importantes, consideram que a Organização possui pouco domínio.

Este estudo pretendeu trazer contribuições para melhor orientar as ações do HUB, no sentido de aprimorar seu desempenho futuro.

Espera-se que a pesquisa aqui apresentada contribua para o desenvolvimento de políticas e ações futuras que elevem a excelência dos serviços prestados pelo HUB, servindo, também, como sugestão e subsídio para a realização de futuras trabalhos referentes a tão importante tema. 


\section{REFERÊNCIAS}

BORBA, V. R. Administração Hospitalar: princípios básicos. São Paulo: CEDAS, 1991.

BORGES-ANDRADE et, al. Treinamento, desenvolvimento e educação em organizações de trabalho: fundamentos de gestão de pessoas. Porto Alegre: Artmed, 2006.

BRANDÃO H. P.; BAHRY C. P. Gestão por competências: métodos e técnicas para mapeamento de competências, Revista do Serviço Público Brasília, Brasília, v. 56, p. 179-194, abr./jun., 2005.

BRANDÃO, H. P.; BORGES-ANDRADE, J.E.B. et al. Causas e efeitos da expressão de competências no trabalho: Para entender melhor a noção de competência. RAM Revista de Administração Mackenzie, Brasília. v. 8, n. 3, p. 32-49, jul./ago., 2007.

BRANDÃO, H. P.; GUIMARÃES, T. A. Gestão de competências e gestão de desempenho: Tecnologias Distintas ou Instrumentos de um mesmo construto? RAE - Revista de Administração de Empresas (FGV), São Paulo, v. 41, n. 1, p. 8-15, jan./mar., 2001.

BRASIL. Constituição (1988). Constituição da República Federativa do Brasil. $1^{a}$ ed. Brasília: Senado Federal, Centro Gráfico, 1988.

BRESSER-PEREIRA, L. C. B.. Da administração pública burocrática à gerencial. Revista do Serviço Público, Brasília, 49, n.1, p.5-42, jan./mar.1998.

A reforma do Estado nos anos 90: lógica e mecanismos de controle. Cadernos Mare da Reforma do Estado, n. 1, Brasília: Ministério da Administração Federal e Reforma do Estado, 1997.

BRUNO-FARIA, M.F.; BRANDÃO, H. P. Gestão de competências: identificação de competências relevantes a profissionais da área de T\&D de uma organização pública do Distrito Federal. Revista de Administração Contemporânea, Rio de Janeiro, v. 7, n. 3, p. 35-56, jul./set., 2003.

CARBONE, P. P. et al. Gestão por competências e gestão do conhecimento. 2 . ed. -Rio de Janeiro : Editora FVG, Série Gestão de Pessoas, 2006.

CHIAVENATO, I. Administração de recursos humanos. São Paulo: Atlas, 1993.

FLEURY, A. C. C.; FLEURY, M. T. L. Construindo o conceito de competência, RACRevista de Administração Contemporânea, Edição Especial, 2001:183-196.

FLEURY, A. C. C.; FLEURY, M. T. L. Estratégias empresariais e formação e competências, 3 ed, São Paulo: Atlas, 2007.

FOUCAULT, M. O nascimento do hospital,. In Microfísica do poder. Graal, Rio de Janeiro, 1981. pp. 99-111 
GASKELL, G. Pesquisa qualitativa com texto, imagem e som: um manual prático; tradução de Pedrinho A. Guareschi. - Petrópolis, RJ : Vozes, 2002.

GIL, A. C.; Métodos e técnicas de pesquisa social. 4 ed. São Paulo: Atlas, 1994.

GURGEL JÚNIOR, G. D.; VIEIRA, M. M. F. Qualidade total e administração hospitalar: explorando disjunções conceituais. 2002, Disponível em: http://www.scielo.br/pdf/csc/v7n2/10251.pdf. Acesso em 04 maio de 2008.

HAMEL, G.; PRAHALAD, C.K. Competindo pelo futuro: Estratégias inovadoras para obter o controle do seu setor e criar os mercados de amanhã. 10 ed. Rio de Janeiro: Campus, 1997.

HOUAISS, A. Dicionário Houaiss da língua portuguesa. 2. ed. Rio de Janeiro: Objetiva, 2004.

MAUDONNET, R. Administração Hospitalar. Rio de Janeiro: Cultura Médica, 1988.

MEIRELLES, H. L. Curso de Direito Administrativo. São Paulo: Malheiros, 2000.

MINTZBERG HA. Adhocracia . In:_. Criando organizações eficazes: estruturas em cinco configurações. São Paulo, São Paulo, 1995.

RABECHINI JUNIOR, R.; CARVALHO, M.M. et al. Perfil das competências em equipes de projetos. RAE - Revista de Administração de Empresas-Eletrônica. São Paulo. Fundação Getúlio Vargas. v. 2, n. 1. jan./jun., 2003.

ROBBINS, Stephen Paul. Comportamento organizacional. 9 ed. São Paulo: Prenticehall, 2002.

TACHIZAWA, T.; SCAICO, O. Organização Flexível. São Paulo: Atlas, 1997.

VERGARA, S.C. Começando a definir a metodologia. In: Projetos de

Pesquisa em Administração. 3 ed.; São Paulo : Atlas, 2000. cap. 4, p. 46-53. 


\section{APÊNDICES}




\section{APÊNDICE A \\ ROTEIRO DE ENTREVISTAS}

\section{MAPEAMENTO DAS COMPETÊNCIAS ORGANIZACIONAIS DE UM HOSPITAL UNIVERSITÁRIO E DE SUAS PRINCIPAIS UNIDADES}

Este estudo faz parte do trabalho final do curso de Especialização em Gestão Universitária, na Universidade de Brasília.

A sua contribuição será fundamental para o nosso estudo. Pedimos permissão para gravar a entrevista. Garantimos que as informações aqui prestadas não serão utilizadas para outro fim, que não o da pesquisa.

O objetivo de nosso estudo é identificar as competências organizacionais necessárias à concretização dos objetivos do Hospital Universitário de Brasília (HUB). Essas competências poderão orientar as ações do HUB, no sentido de aprimorar o seu desempenho futuro.

Decidimos entrevistá-lo por ser responsável, dentre outras coisas, pelo planejamento estratégico, elaboração de cenários, formulação de políticas da organização e desenvolvimento profissional do Hospital.

Neste estudo, competência organizacional é compreendida como:

"Atributo subjacente à organização, que the permite atingir seus objetivos estratégicos" (BRUNO-FARIA; BRANDÃO, 2003, p.54).

Exemplo de competência organizacional responsável pela promoção de ações de TD\&E-Treinamento, Desenvolvimento e Educação para servidores públicos (BRUNO-FARIA; BRANDÃO, 2003, p. 42).

- Identificação de necessidades de desenvolvimento profissional dos servidores públicos;

- Estímulo ao auto desenvolvimento e à profissionalização dos servidores públicos; e

- Desenvolvimento de competência profissionais dos servidores públicos. 


\section{Perguntas:}

Quais as competências necessárias ao HUB para que cumpra os seus objetivos estratégicos? De que o HUB deve ser capaz?

Características pessoais e profissionais dos respondentes:

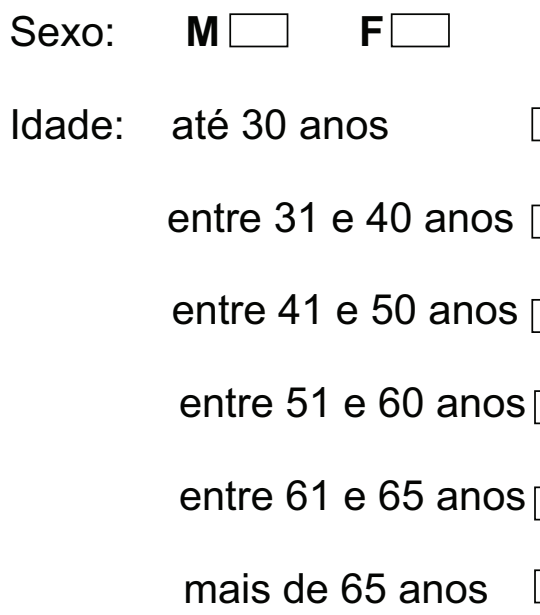




\section{APÊNDICE B QUESTIONÁRIO}

Brasília, 26 de maio de 2008.

Senhor (a) Chefe,

Somos alunas do curso de Especialização em Gestão Universitária, promovido pela Faculdade de Economia, Administração, Contabilidade e Ciências da Informação e Documentação (FACE). Estamos realizando uma pesquisa com o objetivo de identificar as competências organizacionais necessárias à concretização dos objetivos do Hospital Universitário de Brasília-HUB.

Pedimos a sua colaboração no sentido de responder este questionário. Não é necessário identificar-se. A sua contribuição será fundamental para o nosso estudo. Garantimos que as informações prestadas não serão utilizadas para outro fim, que não o da pesquisa.

Os resultados deste trabalho poderão orientar as ações do HUB, no sentido de aprimorar o seu desempenho futuro. Sua participação é muito importante.

Agradecemos a sua colaboração e colocamo-nos à disposição para qualquer esclarecimento que se fizer necessário.

Atenciosamente,

Denise de Sousa Vieira

Maria Lúcia Soares

Tel: 3448-5419/5437 


\section{Identificação das competências organizacionais do Hospital Universitário de Brasília-HUB e de suas principais unidades.}

A seguir há uma lista de competências referentes ao HUB identificadas em uma primeira etapa da pesquisa. Gostaríamos de saber sua opinião sobre o grau de importância dessas competências para o Hospital, assim como quanto o HUB possui essas competências desenvolvidas.

Neste estudo, competência organizacional é compreendida como: "Atributo subjacente à organização, que lhe permite atingir seus objetivos estratégicos" (BRUNO-FARIA; BRANDÃO, 2003, p. 54).

Por favor, escolha um número de UM a CINCO na primeira escala à direita de cada item, a fim de indicar o quanto você considera tal competência importante para o HUB e na segunda escala à direita o quanto o HUB domina tal competência. Por favor, utilize as escalas abaixo e marque com um $X$ as suas opções de respostas para cada item.

ESCALAS DE RESPOSTAS

\begin{tabular}{|l|l|}
\hline \multicolumn{1}{|c|}{ Graus de importância ( $)$} & \multicolumn{1}{c|}{ Graus de domínio ( D ) } \\
\hline 1 Sem importância & 1 Sem domínio \\
\hline 2 Pouca importância & 2 Pouco domínio \\
\hline 3 Média importância & 3 Médio domínio \\
\hline 4 Muita importância & 4 Muito domínio \\
\hline 5 Extrema importância & 5 Total domínio \\
\hline
\end{tabular}




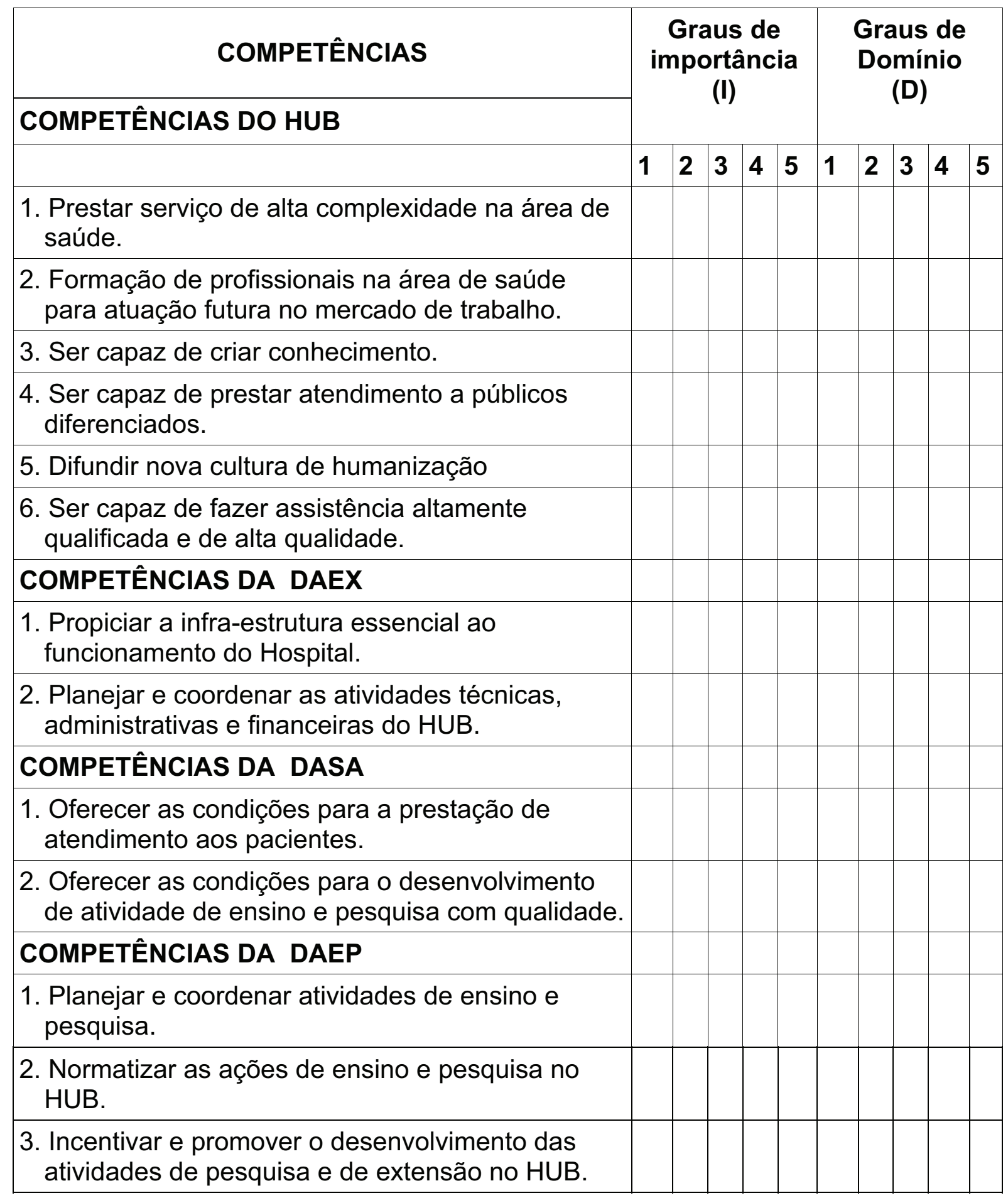


CASO CONSIDERE QUE EXISTAM OUTRAS COMPETÊNCIAS NÃO RELACIONADAS ACIMA, POR FAVOR, ACRESCENTE A SEGUIR:

\section{COMPETÊNCIAS DO HUB}

\section{COMPETÊNCIAS DA:}

- DASA

- DAEP

- DAEX

Como última colaboração no presente instrumento, pedimos a gentileza de responder às questões abaixo que nos ajudarão a caracterizar os participantes da pesquisa.

1.Sexo

( ) masculino

( ) feminino

2. Idade ...........anos

3. Escolaridade

( ) primeiro grau completo

( ) segundo grau completo

( ) superior completo. Curso:

( ) especialização em

( ) mestrado em.

( ) doutorado em

4. Função:

5.Tempo de serviço no UnB:

6. Tempo de serviço no HUB:

Muito obrigado!

OBS.: Pedimos a gentileza de responder o questionário até o dia 26 de maio de 2008 e avisar-nos pelo telefone 3448-5419 ou por e-mail: mlsoares@unb.br ou denvieira@unb.br para que possamos buscá-lo. 